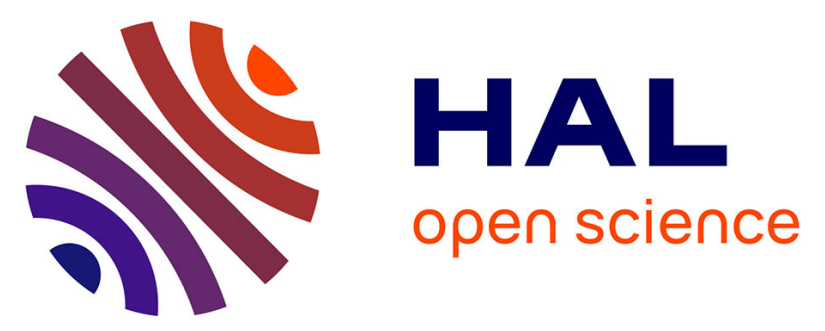

\title{
Dynamic Pore-Scale Dissolution by CO 2 -Saturated Brine in Carbonates: Impact of Homogeneous Versus Fractured Versus Vuggy Pore Structure
}

\author{
Yongfei Yang, Yingwen Li, Jun Yao, Stefan Iglauer, Linda Luquot, Kai
} Zhang, Hai Sun, Lei Zhang, Wenhui Song, Zhiyu Wang

\section{To cite this version:}

Yongfei Yang, Yingwen Li, Jun Yao, Stefan Iglauer, Linda Luquot, et al.. Dynamic Pore-Scale Dissolution by CO 2 -Saturated Brine in Carbonates: Impact of Homogeneous Versus Fractured Versus Vuggy Pore Structure. Water Resources Research, 2020, 56 (4), pp.e2019WR026112. 10.1029/2019WR026112 . hal-02912530

\section{HAL Id: hal-02912530 \\ https://hal.umontpellier.fr/hal-02912530}

Submitted on 6 Aug 2020

HAL is a multi-disciplinary open access archive for the deposit and dissemination of scientific research documents, whether they are published or not. The documents may come from teaching and research institutions in France or abroad, or from public or private research centers.
L'archive ouverte pluridisciplinaire HAL, est destinée au dépôt et à la diffusion de documents scientifiques de niveau recherche, publiés ou non, émanant des établissements d'enseignement et de recherche français ou étrangers, des laboratoires publics ou privés. 


\section{Water Resources Research}

\section{RESEARCH ARTICLE 10.1029/2019WR026112 \\ Key Points: \\ - The impact of limestone pore \\ Dynamic Pore-Scale Dissolution by $\mathrm{CO}_{2}$-Saturated Brine in Carbonates: Impact of Homogeneous Versus Fractured Versus Vuggy Pore Structure} structure on reactive transport was analyzed experimentally and computationally

- The dissolution patterns of homogeneous, fractured, and vuggy carbonate rocks are quantified and discussed in detail

- Increasing complexity of the pore geometry leads to more nonuniform dissolution

Correspondence to:

Y. Yang,

yangyongfei@upc.edu.cn

Citation:

Yang, Y., Li, Y., Yao, J., Iglauer, S., Luquot, L., Zhang, K., et al (2020). Dynamic pore-scale dissolution by $\mathrm{CO}_{2}$-saturated brine in carbonates: Impact of homogeneous versus fractured versus vuggy pore structure. Water Resources Research, 56, e2019WR026112. https://doi.org/ 10.1029/2019WR026112

Received 8 AUG 2019 Accepted 14 MAR 2020 Accepted article online 17 MAR 2020

2020. American Geophysical Union. All Rights Reserved.

\author{
Yongfei Yang ${ }^{1,2}$ (D), Yingwen $\mathrm{Li}^{1,2}$, Jun Yao ${ }^{1,2}$, Stefan Iglauer $^{3}$ (D) Linda Luquot ${ }^{4}$, Kai Zhang ${ }^{1,2}$ (D), \\ Hai Sun ${ }^{1,2}$, Lei Zhang ${ }^{1,2}$ (D), Wenhui Song ${ }^{1,2}$ (D), and Zhiyu Wang ${ }^{1,2}$ \\ ${ }^{1}$ Key Laboratory of Unconventional Oil and Gas Development, China University of Petroleum (East China), Ministry of \\ Education, Qingdao, China, ${ }^{2}$ Research Center of Multiphase Flow in Porous Media, School of Petroleum Engineering, \\ China University of Petroleum (East China), Qingdao, China, ${ }^{3}$ School of Engineering, Petroleum Engineering Discipline, \\ Edith Cowan University, Joondalup, Western Australia, Australia, ${ }^{4}$ Université Montpellier, CNRS, Geosciences \\ Montpellier Laboratory, Montpellier, France
}

\begin{abstract}
Limestone pore structure strongly influences dissolution and associated reactive transport. These effects are critical in limestone diagenesis and but also in engineering operations such as carbon capture and storage (CCS). However, detailed studies on how $\mathrm{CO}_{2}$-enriched (acidic) brine changes this pore structure at relevant reservoir storage conditions are very limited. Thus, to provide further quantitative information and more fundamental understanding about these key processes, we studied the dissolution patterns of a homogeneous, a fractured, and a vuggy limestone when flooded with $\mathrm{CO}_{2}$-saturated brine at representative storage conditions. The pore structured of these limestones showed drastically different responses to the acidic brine flood. As such, preferential channels surrounded by branched channels were formed in the homogeneous sample, while fractures became the main flow path in the fractured sample. In contrast, only one dominant channel formed in the vuggy sample, which resulted in a sharp permeability increase. These dissolution patterns reflect the associated Damköhler number, which significantly lower in the homogeneous, representing uniform dissolution. However, after injecting sufficient reactive fluid (1,000 PV), this uniform dissolution pattern transformed into a single preferential channel growth. Moreover, we conclude that increasing complexity of the pore geometry leads to more nonuniform dissolution. These dissolution patterns indicate the effect of initial pore structure on preferential channel growth and reaction transport. Our work provides key fundamental data for further quantifying limestone dissolution patterns in CCS, indicating that the $\mathrm{CO}_{2}$ injection may cause the reactivation of geological faults and damage around wellbore, thus aids in the implementation of industrial-scale CCS.
\end{abstract}

\section{Introduction}

Carbon capture and storage has been recognized as the primary solution for mitigating anthropogenic $\mathrm{CO}_{2}$ emissions (Bachu, 2000; Lackner, 2003), and deep saline aquifers are the largest potential target reservoirs (Celia et al., 2015; Zhang et al., 2019). Dissolution trapping is one of the secure capture mechanisms where the buoyant $\mathrm{CO}_{2}$ dissolves in the formation brine; this acidified brine sinks deep into the reservoir and leads to the partial dissolution of carbonate reservoirs (Celia et al., 2015; Iglauer, 2011; Miao et al., 2020). In order to assess $\mathrm{CO}_{2}$ storage capacity and security, a micrometer pore-scale analysis of the reactive transport processes is required to account for the complex phenomena occurring in these limestone formations ( $\mathrm{Li}$ et al., 2006; Li et al., 2008; Li et al., 2014; Menke et al., 2015; Noiriel \& Daval, 2017).

Carbonate dissolution is controlled by many factors including physical heterogeneity at multiple scales, chemical heterogeneity (spatial distribution of minerals), temperature, pressure, initial $\mathrm{pH}$, and flow rates. In this paper, the dissolution pattern of three carbonate rocks with typical pore structure (homogeneous, fractured, and vuggy) are discussed.

As such a number of previous studies investigated pore-scale reactive transport (Gharbi et al., 2013; Lebedev et al., 2017; Menke et al., 2016; Noiriel et al., 2004; Noiriel et al., 2005). It was shown that 
dissolution is uniform in homogeneous limestone, while channels ("wormholing") are formed in heterogeneous carbonate (Al-Khulaifi et al., 2019; Maheshwari et al., 2013). Especially in single mineral systems, the dissolution regime is structure dependent. In the works of Menke et al. (2015), the dissolution of a millimeter-scale limestone with a relatively simple pore structure at reservoir conditions was captured by microcomputed tomography (micro-CT) imaging and they found that the dissolution along the sample axis was uniform. Menke et al. (2016) examined the dissolution of two heterogeneous carbonates to investigate the impact of initial pore structure and found a new dissolution regime: The lower porosity sample experienced fast channel formation, in this case, the formation conditions were dependent on initial pore topology rather than flow rates. Thus far, most single-mineral imaging of $\mathrm{CO}_{2}$ acidic brine dissolution is featured by homogeneous or heterogeneous limestones. Luquot et al. (2014) performed a set of four reactive flow experiments to describe the mass transfer process and the exponent of the permeability-porosity relationship. Smith et al. (2017) observed stable dissolution fronts in the more homogeneous dolomites and preferential flow paths in heterogeneous dolomites; they believed the porosity-permeability relationship is sensitive to pore space heterogeneity. However, the dissolution processes in fractured and vuggy carbonates are not fully understood, although limestones are typically fractured and contain large pores ("vugs"). Hence, the main goal of this study is to investigate how fractured and vuggy limestone pore structure impact on the reactive transport processes; this is then compared with the homogeneous benchmark case.

With the deepening of research, factors other than initial pore structure are added to the experiments of reactive transport. Luquot and Gouze (2009) reported nonuniform dissolution features near the injection well, while uniform dissolution was observed far from the injection well. However, the main factor controlling the two dissolution patterns is reactive brine with different partial pressures of $\mathrm{CO}_{2}$ rather than pore structure. Menke et al. (2017) described reaction in both homogeneous and heterogeneous carbonates for multiple brine $\mathrm{pH}$ and found that channeling was faster with increasing heterogeneity and decreasing $\mathrm{pH}$. In another work, Al-Khulaifi et al. (2018) combined pore-scale experimental observation and modeling to characterize reactive transport in two heterogeneity groups dolomite under two flow rates. Al-Khulaifi et al. (2017) imaged the dissolution of the composite core to examine the effect of physical and chemical heterogeneity on dissolution regime and effective reaction rate. In recent work, Al-Khulaifi et al. (2019) studied the impact of physical and chemical heterogeneity on the reaction rates in a multimineral carbonate.

Several studies have investigated dissolution in fractured carbonates (Andreani et al., 2008; Gouze et al., 2003; Szymczak \& Ladd, 2009) and flow behavior in vuggy rocks (Arbogast et al., 2004; Kamath et al., 1998; Moctezuma-Berthier \& Fleury, 2000; Zhang et al., 2005). They found that fracture dissolution regimes depend on fracture morphology, flow patterns, and mineralogical composition of the rock matrix. In the experiments of Detwiler (2008), Dijk et al. (2002), Ellis et al. (2011), and Noiriel et al. (2007), the dissolution of fractured carbonate rocks by flowing $\mathrm{CO}_{2}$-saturated brine was captured with nuclear magnetic resonance and micro-CT imaging. The intent was to identify the correlations between dissolution patterns, the fracture morphology, and mineralogical composition of the rock matrix by assessing spatial variability of dissolution rates and reactive surface changes. It was shown that at high Damköhler numbers, the dissolution patterns were dominated by the flow path. A large-scale fast channel was formed in the areas with little dissolution and slow closure of the fracture surfaces. By contrast, the low Damköhler experiment exhibited relatively uniform dissolution across the width of the fracture, with locally enhanced dissolution in small aperture regions. The dissolution patterns depended mainly on the mineral composition of the rock matrix. Finally, carbonate dissolution rate decreased due to reorganization of clay minerals. Izgec et al. (2010) explored the effects of large-scale vugs on carbonate acidizing with micro-CT imaging and numerical simulations. They observed that acid spreads in wormholes through vuggy rocks faster than those in homogeneous rocks and suggested that the local pressure drop created by vug was more important in wormhole flow path formation than the chemical reaction at the pore scale.

As seen above, there are extensive experimental and numerical studies of dissolution processes in limestone, such as wormholing in matrix and channeling in homogeneous, fractured, and vuggy carbonate (including limestone) rocks. However, these studies only carry out experiments or flow simulations in samples with single pore structure. Even if the effect of pore structure heterogeneity was discussed, this heterogeneity cannot represent fractured and vuggy carbonate rocks. Moreover, few studies have compared the dissolution 

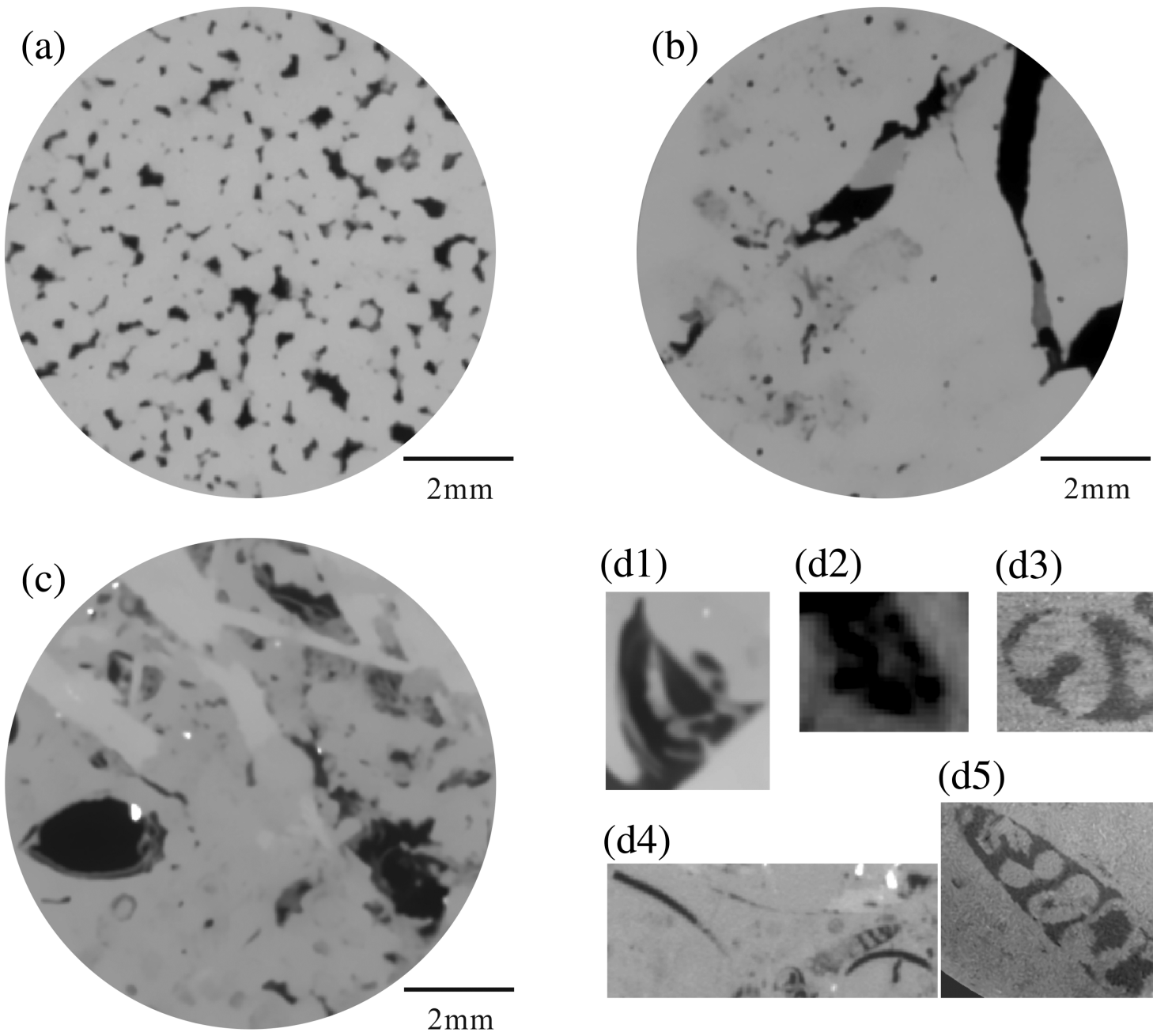

$(\mathrm{d} 3)$

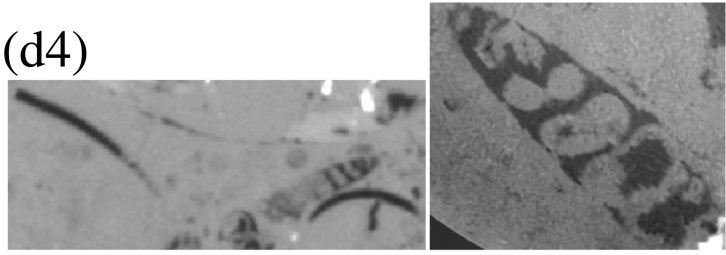

Figure 1. Two-dimensional slices through homogeneous carbonate rock (a), fractured carbonate rock (b), vuggy carbonate rock (c), and biodebris including gastropods (d1 and d4), coral (d2), spotted algae (d3), and foraminifera (d5) at $21.14 \mu \mathrm{m}$ voxel resolution.

patterns, effective reaction rates, porosity and permeability relationship, and the distribution of Damköhler and Péclet numbers in the three typical carbonate rocks.

X-ray microtomography has been successfully used to study the dynamic pore-scale changes induced by $\mathrm{CO}_{2}$-acidified brine injection (Al-Khulaifi et al., 2017; Al-Khulaifi et al., 2018; Gouze \& Luquot, 2011; Lebedev et al., 2017; Luquot \& Gouze, 2009) and pore space characterization (Song et al., 2019; Yang et al., 2019; Yang et al., 2020). In this investigation, we combined experimental and numerical simulation (Lattice Boltzmann) methods and examined the detailed dissolution processes in homogeneous, fractured, and vuggy carbonate rocks. Experimentally, high-resolution in situ X-ray microtomography images were acquired before and after $\mathrm{CO}_{2}$-saturated brine flooding. In addition, for each experimental group, the permeability was simulated for different displacement stages, and associated transport and reaction parameters

Table 1

Petrophysical and Mineralogical Rock Properties

\begin{tabular}{lcccccc}
\hline Sample & Initial pore structure & Porosity $(\%)$ & Permeability $\left(\times 10^{-3} \mu \mathrm{m}^{2}\right)$ & Calcite $(\%)$ & Quartz $(\%)$ & Anhydrite $(\%)$ \\
\hline A & Homogeneous & 9 & 1392.83 & 98 & 2 \\
B & Fractured & 15 & 77.75 & 96 & 4 \\
C & Vuggy & 10.65 & 16.53 & 75 & 0 \\
\hline
\end{tabular}


(a)

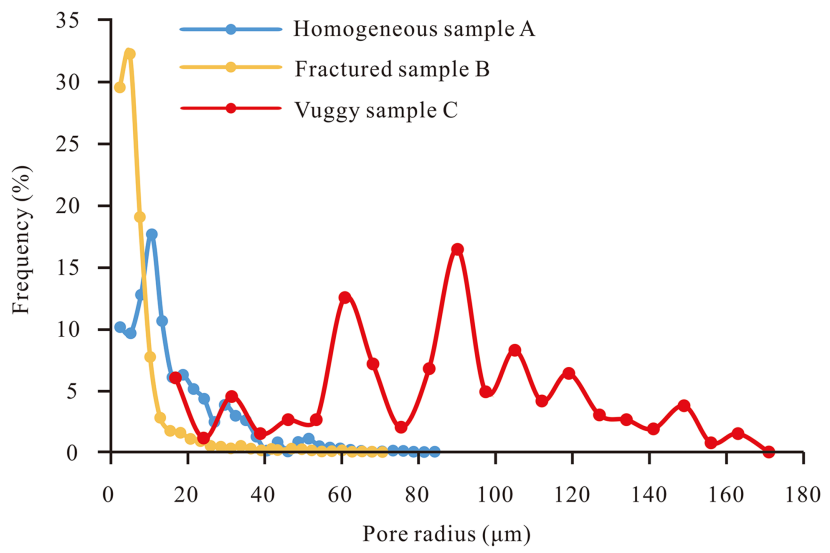

(b)

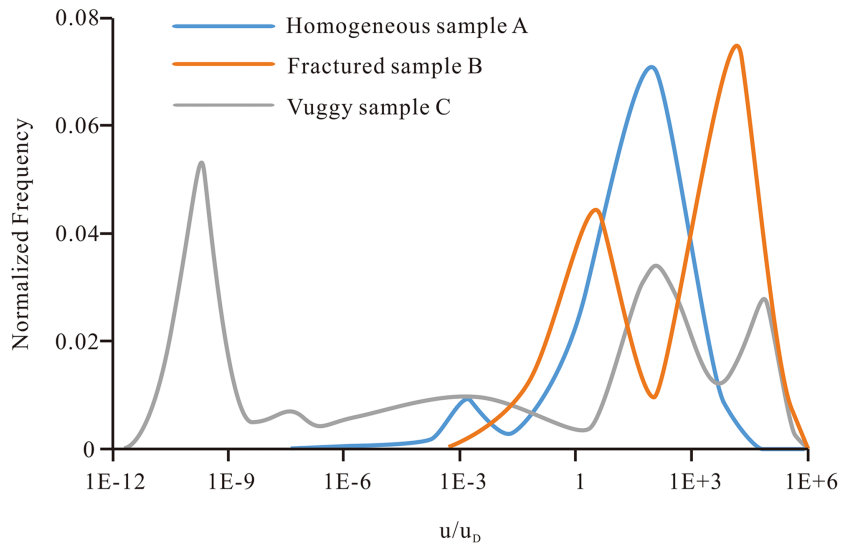

Figure 2. The pore radius distributions (a) at $4.26 \mu \mathrm{m}$ resolution and initial velocity distributions (b) of each sample. Sample A had more homogeneous pore structure, while $\mathrm{B}$ and $\mathrm{C}$ had more heterogeneous pore structure.

(i.e., Péclet and Damköhler numbers, and effective reaction rates) were calculated to quantify the dissolution processes for homogeneous, fractured, and vuggy carbonate rocks. Thus, our study provides dissolution patterns, permeability changes, advection-diffusion effects, and $P e$ - $D a$ distributions for various pore structure. This information is required for accurate predictive modeling, which can determine how the $\mathrm{CO}_{2}$-acidified brine moves in the subsurface. This again is the basis for carbon storage capacity predictions and risk assessments.

\section{Materials and Methods}

\subsection{Carbonate Samples}

Three samples were selected for the reactive transport experiments, these include homogeneous, fractured and vuggy carbonate rocks, respectively. All samples were cylindrical, and $2 \mathrm{~cm}$ long with a $9 \mathrm{~mm}$ diameter. Figure 1 shows X-ray microtomography (micro-CT) grayscale image slices of each carbonate tested. Permeability and porosity were measured by a QKY-II instrument using nitrogen on standard samples and mineral composition was measured by X-ray diffraction instrument (cf. Table 1). Sample A was acquired from the Feixianguan formation deposited at Triassic age. Sample B and Sample C were collected from Northeastern Turkmenistan (both deposited at Jurassic age). Sample B contained natural fractures, and Sample C contained vugs, that is, intergranular dissolved pores. Note that Sample C contained rich biodebris (such as gastropods, foraminifera, brachiopod, spotted algae, and coral); this contributes to the formation of vugs. The petrophysical characteristics of each sample are listed in Table 1. Samples A and B were essentially chemically homogeneous (with minor parts of quartz which is effectively nonreactive), while Sample C was a composite and contained three minerals (note that anhydrite does not react with $\mathrm{CO}_{2}$-acidified brine but dissolves in trace amounts).

\subsection{Sample Heterogeneity Characterization}

Lattice Boltzmann method was used to simulate the associated fluid flow (Sun et al., 2017; Zhang et al., 2019). Thus, to calculate the permeability of the samples, the binary data file of the digital core was imported into a D3Q19 lattice model (Qian et al., 1992; Zhu et al., 2019). Here the distribution function $f_{i}(x)$ represents the average movement of fluid particles. The left part of equation 1 represents the migration of particles, while the right represents the collision of particles, and $\tau$ is the relaxation parameter (equation 2):

$$
\begin{gathered}
f_{i}\left(x+e_{i} \Delta t, t+\Delta t\right)-f_{i}(x, t)=-\frac{1}{\tau}\left[f_{i}(x, t)-f_{i}^{e q}(x, t)\right] \\
\tau=\frac{v}{c_{s}^{2} \Delta t}+0.5
\end{gathered}
$$

where $v$ is the kinematic viscosity of the fluid and $c_{s}\left(c_{s}=\frac{1}{\sqrt{3}}\right)$ represents the lattice pseudo-sound-speed. 


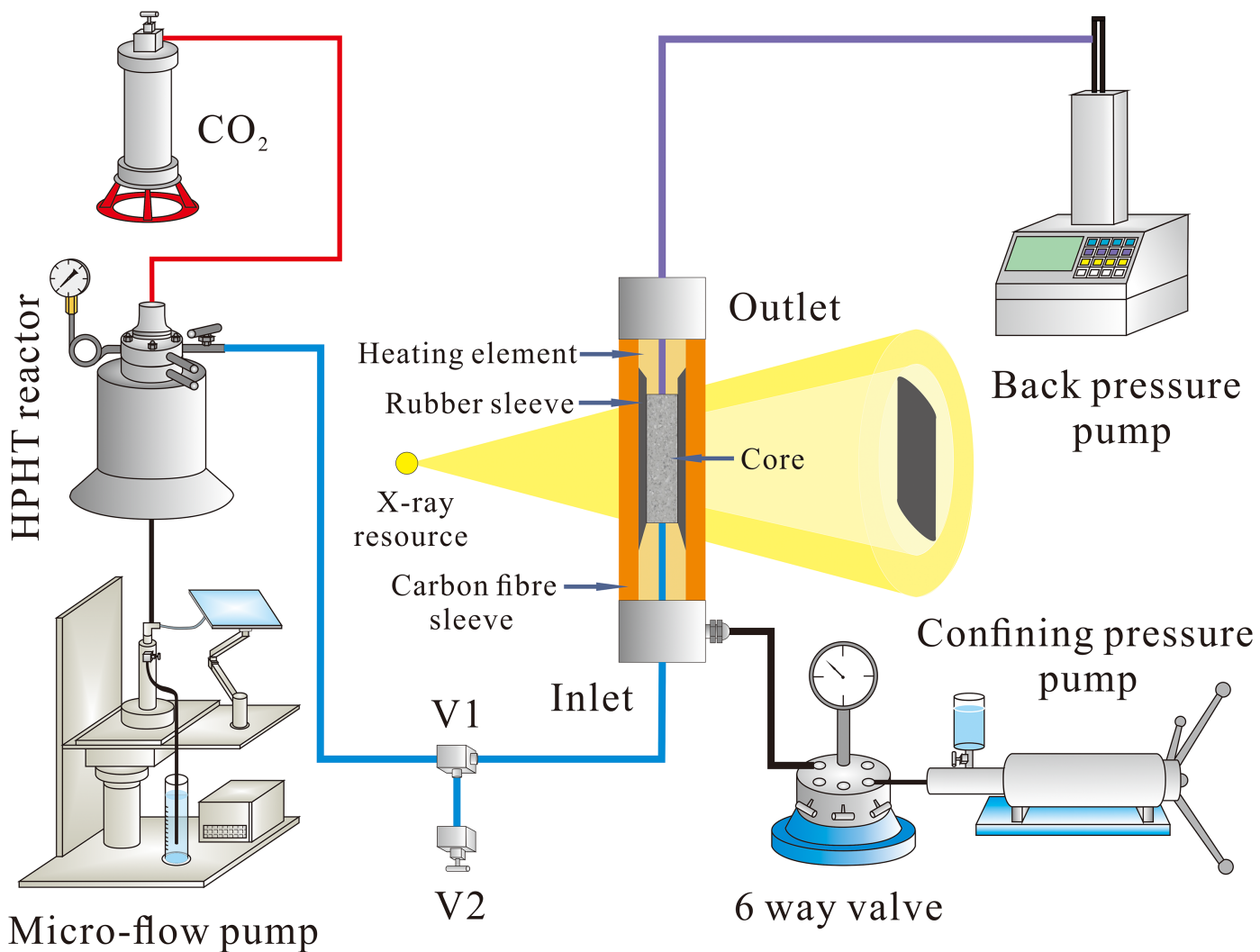

Figure 3. The in situ micro-CT core flooding apparatus used consisted of three pumps, a HPHT reactor, and a core holder.

The $f_{i}^{e q}(x)$ in equation 1 is the equilibrium distribution function of the incompressible D3Q19 model (He \& Luo, 1997):

$$
f_{i}^{\mathrm{eq}}(\mathrm{x})=\omega_{i}\left[\rho(\mathrm{x})+\rho_{0}\left(3\left(e_{i} \cdot \mathrm{u}\right)+\frac{9}{2}\left(e_{i} \cdot \mathrm{u}\right)-\frac{3}{2}(\mathrm{u} \cdot \mathrm{u})\right)\right]
$$

where $\rho_{0}$ is the average fluid density and $\omega_{i}$ is the weight factor in $i$ th direction $\omega_{i}$ for D3Q19 is identified as

$$
\omega_{i}=\left\{\begin{array}{l}
1 / 3, i=0 \\
1 / 18, i=1,2,3,4,5,6 \\
1 / 36, i=7,8,9,10,11,12,13,14,15,16,17,18
\end{array}\right.
$$

Besides, the macrodensity of the fluid $(\rho)$, lattice velocity $(u)$, and macroscopic pressure $(p)$ at each lattice unit were calculated as $\rho(\mathrm{x})=\sum_{i=0}^{18} f_{i}(\mathrm{x}), u=\frac{1}{\rho(\mathrm{x})} \sum_{i=0}^{18} f_{i}(\mathrm{x}) e_{i}$, and $p(x)=c_{s}^{2} \rho(x)$.

Finally, the flow rate $Q\left(\mathrm{~m}^{3} / \mathrm{s}\right)$ was obtained as $Q=\sum_{j=1}^{n} u\left(x_{j}\right) A\left(x_{j}\right)$ where $u\left(x_{j}\right)(\mathrm{m} / \mathrm{s})$ is the velocity at each outlet node and $A\left(x_{j}\right)$ is the area of each lattice at the outlet. The Darcy velocity was calculated as $u_{D}=Q / \sum_{j=1}^{n} A\left(x_{j}\right)$. From these simulations, the velocity distribution was obtained for the lattice space. Note that the initial velocity distribution can characterize the physical heterogeneity.

In this simulation, single-phase fluid was driven by differential pressure. The driven acceleration is $5 \times 10^{-5}$ in $x$ direction, and all units are lattice units (Yang et al., 2020; Zhao et al., 2016). Absolute permeability is independent of the type of fluid; thus, the boundary is static solid boundary. For this boundary, the commonly used method is to bounce back the particles on the boundary, which is called the standard bounce-back scheme. We used this scheme to convert the walls of the porous media to 

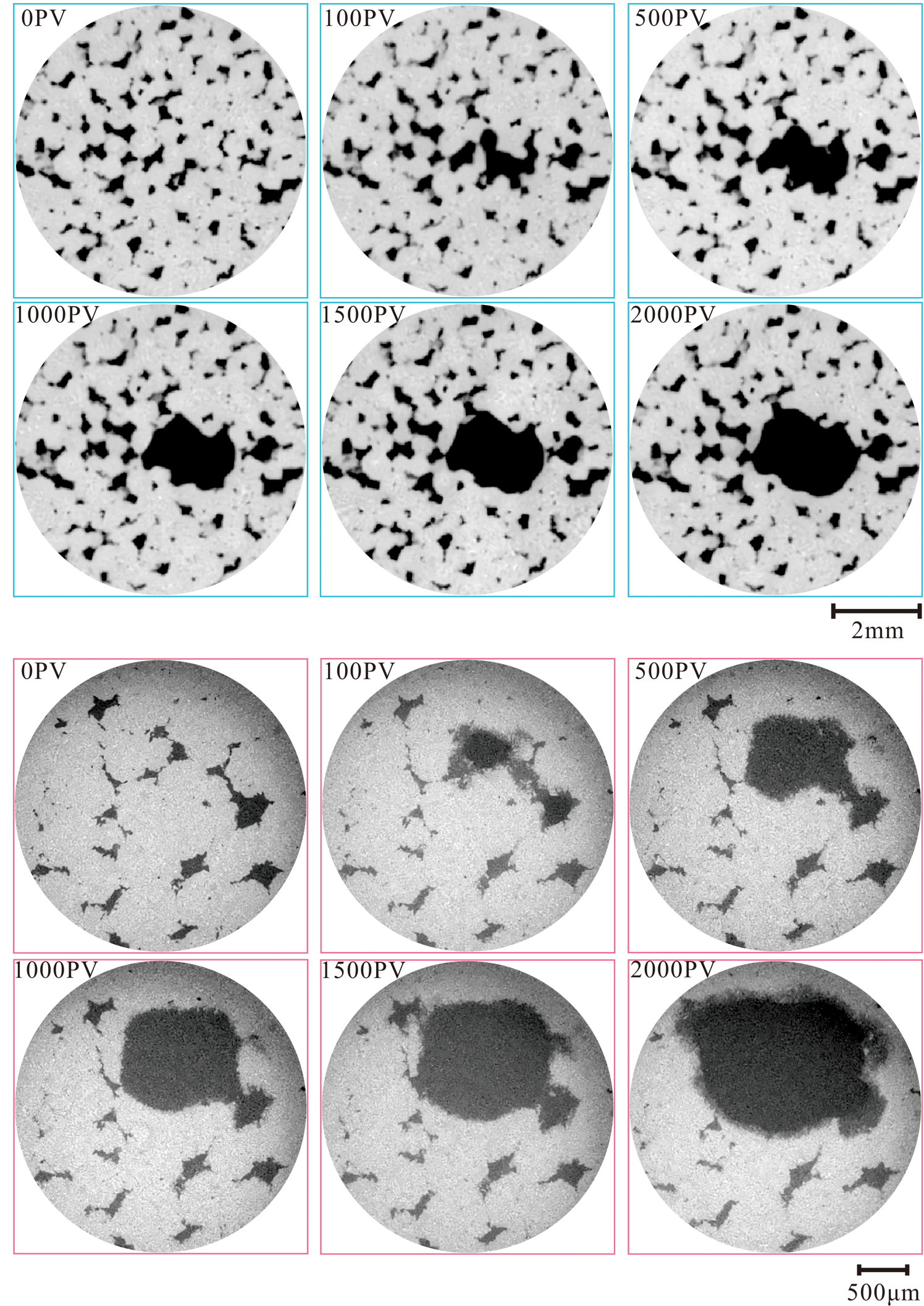

Figure 4. Two-dimensional micro-CT slices through Sample A at 21.14 (blue boxes) and $4.26 \mu \mathrm{m}$ (red boxes) resolution. 

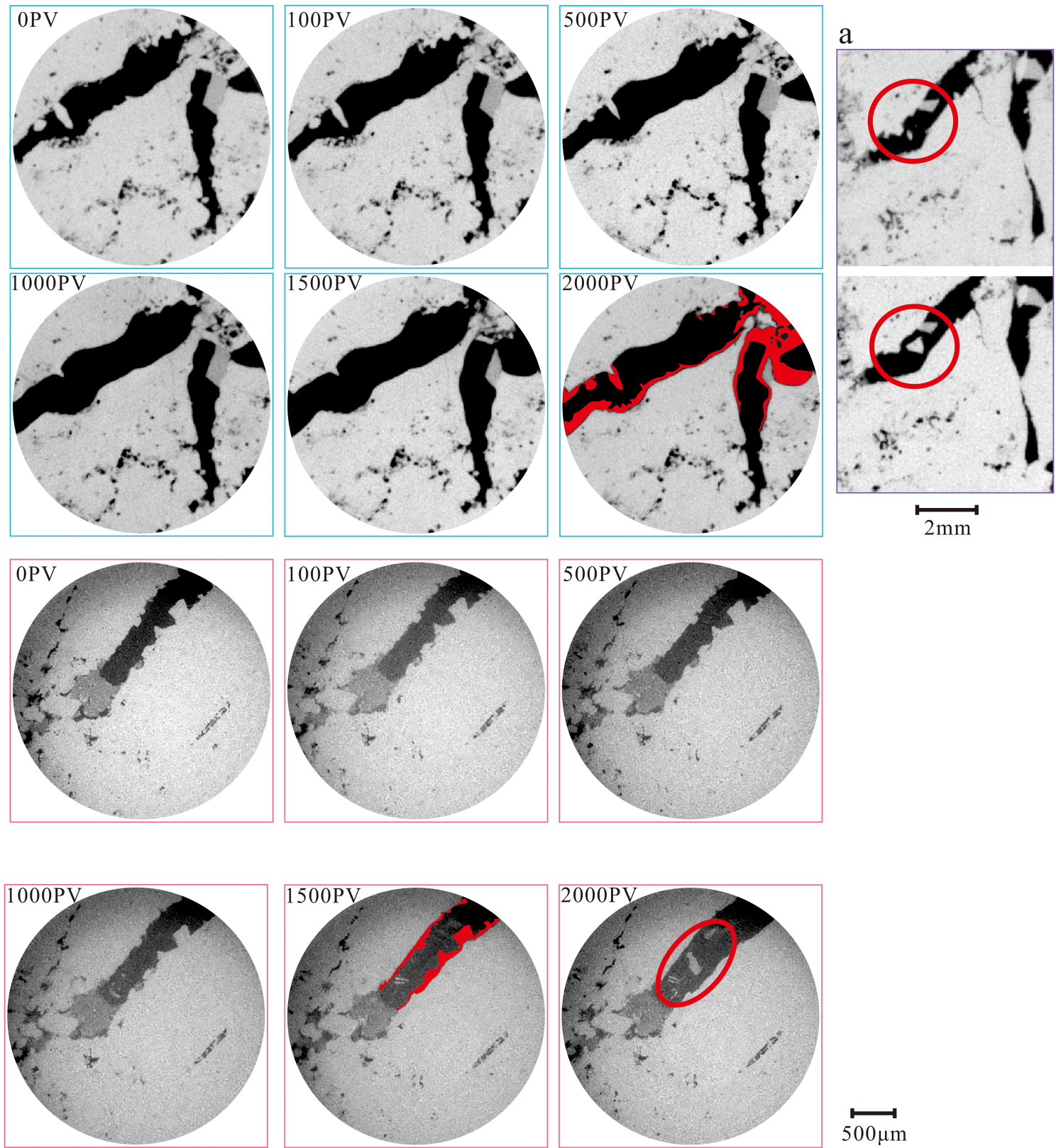

$\stackrel{500 \mu \mathrm{m}}{\longmapsto}$

Figure 5. Two-dimensional micro-CT slices through Sample B at $21.14 \mu \mathrm{m}$ (blue boxes) and $4.26 \mu \mathrm{m}$ (red boxes) resolution. Red areas indicate reacted (dissolved) voxels; migrated fines appear in the red circle.

bounce-back boundary conditions (Maier \& Bernard, 2010; Ziegler, 1993). In this scheme, the particle will return to the fluid node along the original path when it touches a wall node. The speed and density of the fluid in the porous medium reaches a steady state until the difference between adjacent times is less than $10^{-6}$. According to Darcy's law, the equivalent permeability of each core was calculated as

$$
K=-\mu \frac{u_{D}}{\nabla p}
$$

Probability density functions can be used to characterize the physical heterogeneity (Bijeljic et al., 2013, 2013). From the simulations we obtained the lattice velocity $u$ (the velocity in each 

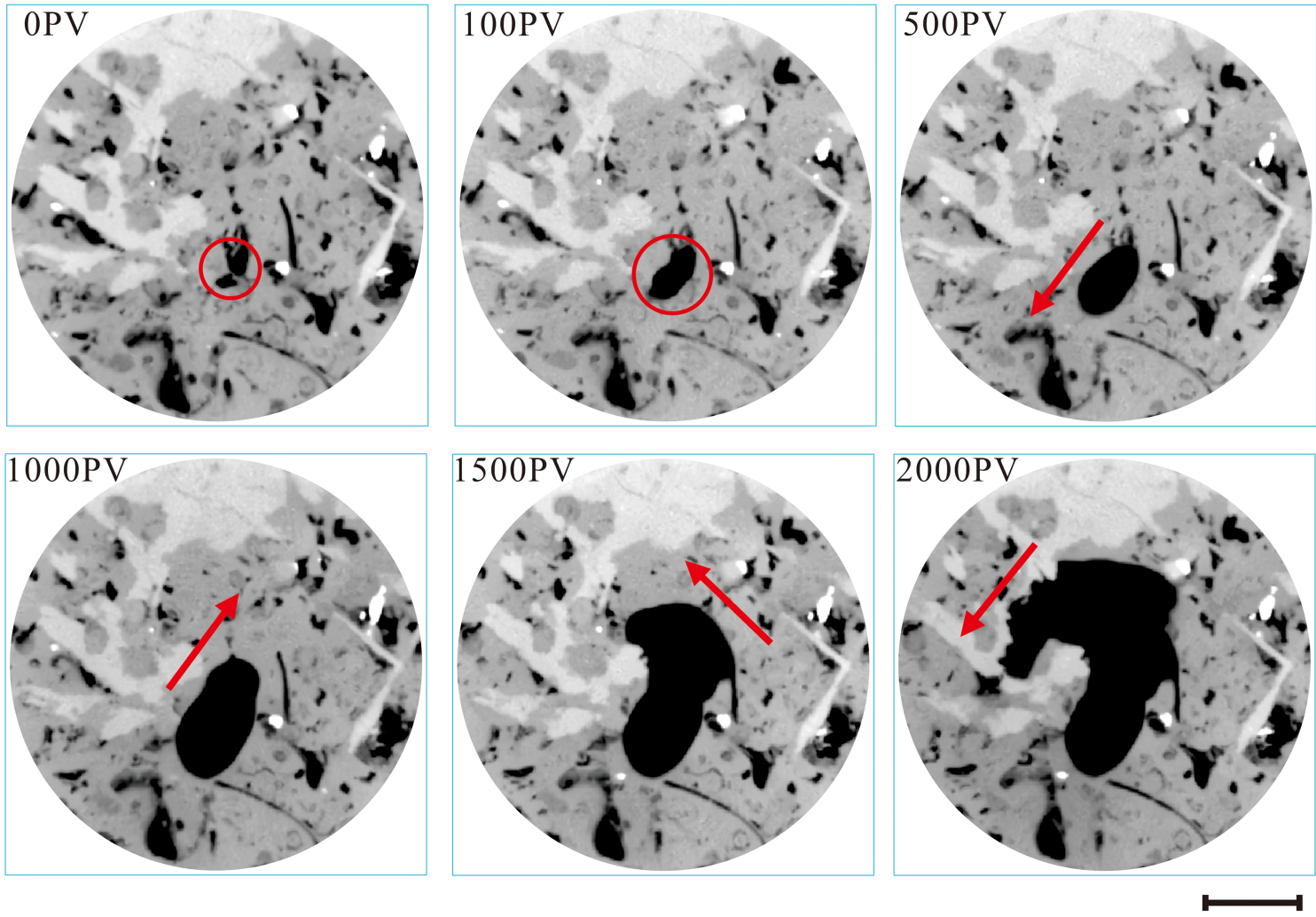

$2 \mathrm{~mm}$

Figure 6. Two-dimensional micro-CT slices through the Sample C at $21.14 \mu \mathrm{m}$ resolution. Red circles represent dissolved hole, and the arrows represent the direction in which the vug grows.

lattice unit), which were divided by the Darcy velocity $u_{D}$, and lattice is generally regarded as a voxel of 3-D image. Through LBM simulation, Darcy velocities of Samples A, B, and C were 1.02E-15, 1.60E -14 , and $3.13 \mathrm{E}-19 \mathrm{~m} / \mathrm{s}$, respectively. Figure 2 shows the velocity distributions of the initial state of the three samples. Moreover, we extracted 3-D pore network model and calculated the pore radius distribution of each sample (Figure 2). Sample A had both single peaks in the distributions of pore radius and initial velocity, which indicates that Sample A is a homogeneous carbonate (Yang et al., 2019; Yang, Wang, et al., 2019). However, the two more heterogeneous distributions had multiple peaks, and the velocity distribution of cavernous sample was broader. The multiple peaks in the pore radius distribution curve reveal that Sample C has strong physical heterogeneity.

\subsection{Experimental Methodology}

A core was placed in a rubber sleeve and sandwiched between two heating elements (which were added upstream and downstream and maintained the core at $50{ }^{\circ} \mathrm{C}$ ). This assembly was inserted into a carbon fiber core holder and a confining pressure of $2 \mathrm{MPa}$ was applied through a separate deionized water pump, Figure 3. The core holder was then connected to the flow system, and the core and flow tubes were vacuumed for $6 \mathrm{hr}$. The $\mathrm{CO}_{2}$-saturated brine was prepared by adding $\mathrm{CO}_{2}$ into a HPHT (high pressure and high temperature) reactor, which had been partially filled with $3 \mathrm{wt} \% \mathrm{NaCl}$ brine. A pressure of $10 \mathrm{MPa}$ and a temperature of $50{ }^{\circ} \mathrm{C}$ was applied and equilibrated brine was taken from the HPHT reactor (open the two-way valve V2) at the beginning of each experiment (El-Maghraby et al., 2012). The $\mathrm{pH}$ of $\mathrm{CO}_{2}$ acidified brine was verified to be 3.5 after testing with PHB-4 portable $\mathrm{pH}$ measuring instrument.

Initially the dry samples were imaged at two resolutions ( $4.26 \mu \mathrm{m}$ and $21.14 \mu \mathrm{m})$ under a confining pressure of $2 \mathrm{MPa}$. The core samples were then gradually pressurized to $8 \mathrm{MPa}$ pore pressure by a back pressure pump while confining pressure was always $2 \mathrm{MPa}$ higher than the pore pressure. Subsequently, $\mathrm{CO}_{2}$-saturated brine was injected at $0.1 \mathrm{~mL} / \mathrm{min}$ with a high-precision syringe pump. The cores were then imaged again 


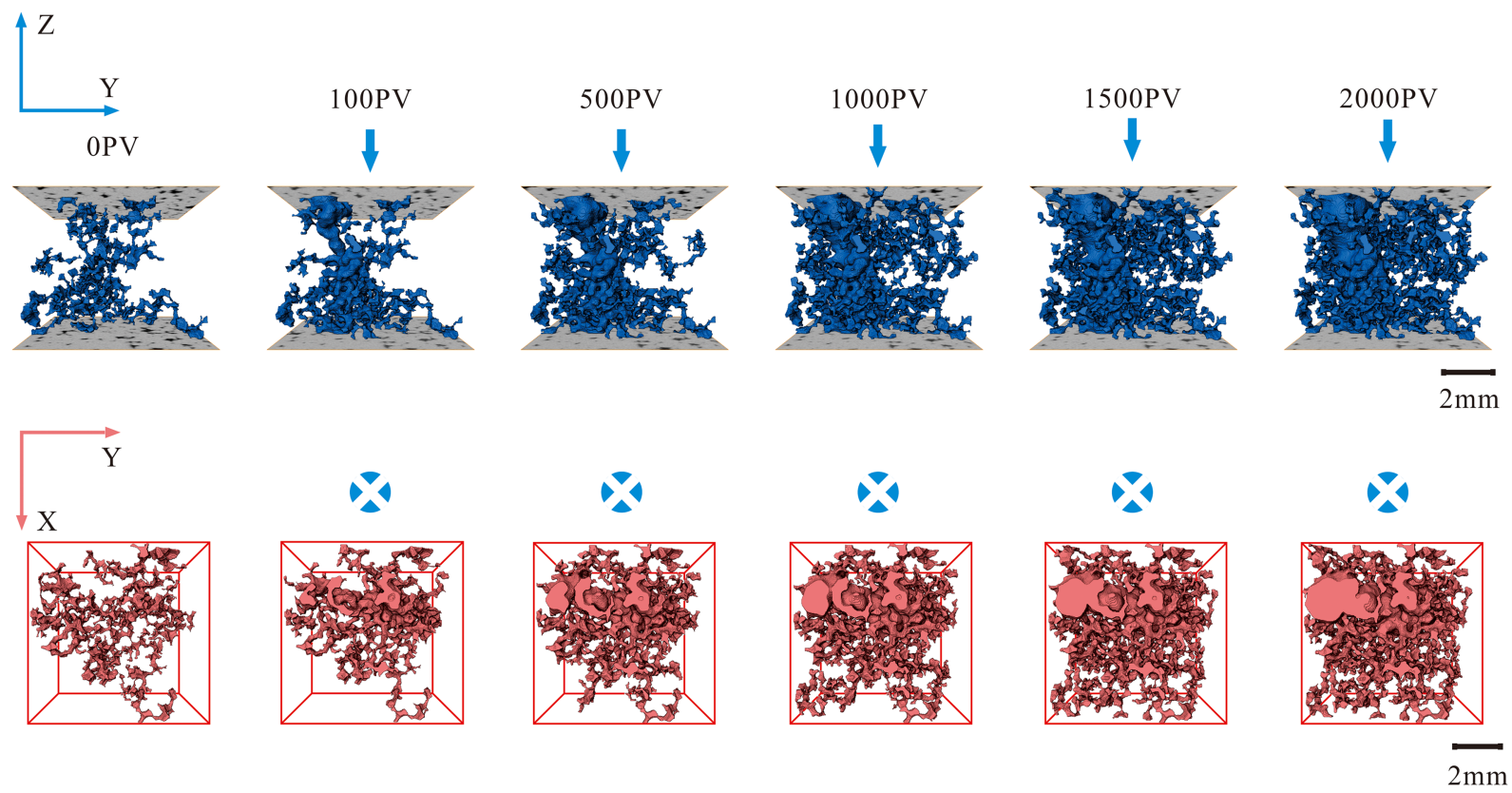

Figure 7. Three-dimensional visualizations $\left(300 \times 300 \times 236\right.$ voxels $\left.=6.34 \mathrm{~mm} \times 6.34 \mathrm{~mm} \times 4.99 \mathrm{~mm}=200.66 \mathrm{~mm}^{3}\right)$ in $X Y$ and $Y Z$ direction of the main pore space in the homogeneous limestone. The arrow represents the direction of $\mathrm{CO}_{2}$ acidified brine injection, and the cross represents the injection direction perpendicular to the $X Y$ plane (21.14 $\mu \mathrm{m}$ resolution images).

multiple times during the flood, after injecting $100 \mathrm{PV}$ (pore volumes), 500, 1,000, 1,500, and 2,000 PV at the same high resolutions (4.26 and $21.14 \mu \mathrm{m})$ to analyze the pore structural change (Iglauer \& Lebedev, 2018). The raw tomograms were filtered with a 3-D nonlocal means filter to denoise the images (Buades et al., 2005; Yang et al., 2019), and the phases were segmented with a watershed algorithm based on different gray values (Schlüter et al., 2014; Yang et al., 2020). The pore phase was then extracted from the image for quantitative analysis, and the pore volume fraction (i.e., $\phi_{\mathrm{CT}}$ ) was measured by counting the pore voxels and dividing them through the rock voxels.

\subsection{Determination of Effective Reaction Rate, Péclet, and Damköhler Number}

Péclet number $(\mathrm{Pe})$ is defined as the ratio between the rate of mass transport of the solute to its molecular diffusion rate. We express $u_{a v g}$ as the average pore velocity of the fluid flow, calculated by dividing the Darcy velocity by $\phi_{C T} ; \phi_{C T}$ is the porosity measured on the segmented images. $L_{c}(\mathrm{~m})$ is a characteristic length given by $L_{c}=\pi / S$ where $S\left(\mathrm{~m}^{-1}\right)$ is the specific surface area measured on micro-CT images (Mostaghimi et al., 2012); and $D_{m}$ is the molecular diffusion coefficient which has a value of $7.5 \times 10^{-10} \mathrm{~m}^{2} / \mathrm{s}$ for Ca $\mathrm{Ca}^{2+}$ (Luquot \& Gouze, 2009) for these pressure and temperature conditions $\left(10 \mathrm{MPa}, 50{ }^{\circ} \mathrm{C}\right)$.

$$
\begin{gathered}
P e=\frac{u_{a v g} L_{c}}{D_{m}} \\
u_{a v g}=\frac{u_{D}}{\phi_{C T}}
\end{gathered}
$$

Moreover, Damköhler numbers $(D a)$ for the three samples were obtained. $D a$ reflects the relationship between the chemical reaction rate and the mass transport rate, and it can be expressed as (Al-Khulaifi et al., 2019):

$$
D a=\frac{\pi r_{\text {mineral }}}{u_{\text {avg }} n}
$$

where $r_{\text {mineral }}$ is the intrinsic reaction rate, which has a value of $8.1 \times 10^{-4} \mathrm{~mol} / \mathrm{m}^{2} \mathrm{~s}$ for calcite (Peng et al., 2015; Peng et al., 2016), and $n$ represents the molar number of minerals per unit rock volume. 
$\int_{Y} \mathrm{X}_{0 P V}^{Z}$
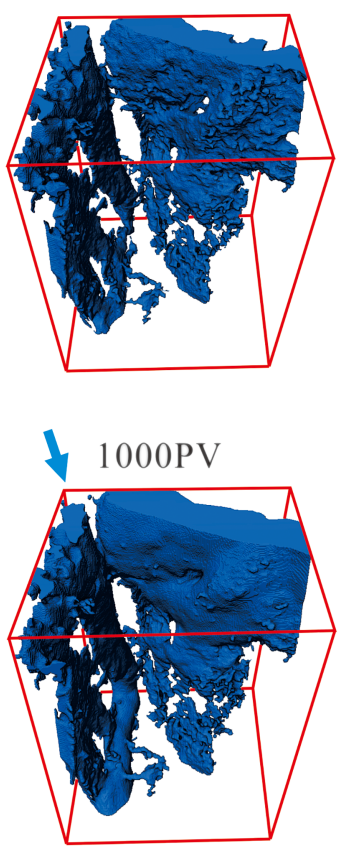
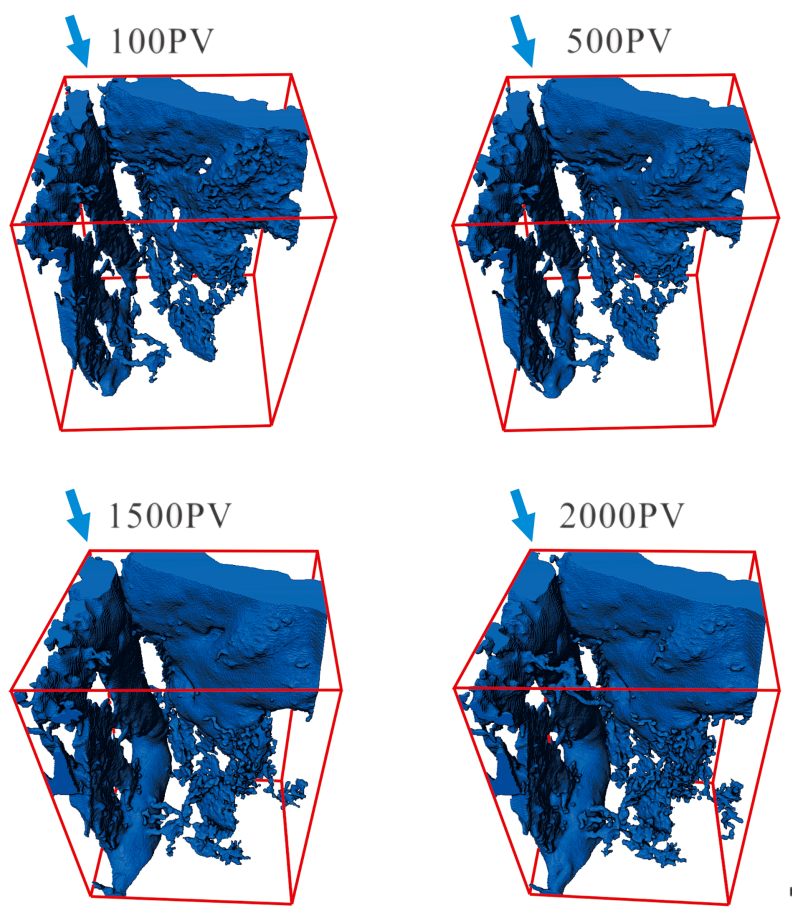

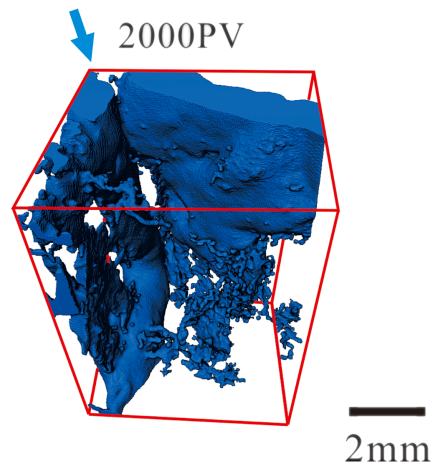

Figure 8. Three-dimensional visualizations $\left(300 \times 300 \times 400\right.$ voxels $\left.=6.34 \mathrm{~mm} \times 6.34 \mathrm{~mm} \times 8.46 \mathrm{~mm}^{2}=340.11 \mathrm{~mm} \mathrm{~m}^{3}\right)$ of the pore space in the fractured limestone. The arrow represents the direction of $\mathrm{CO}_{2}$ acidified brine injection.

$$
n=\frac{\rho_{\text {mineral }} f\left(1-\phi_{C T}\right)}{M_{\text {mineral }}}
$$

where the density $\left(\rho_{\text {mineral }}\right)$ of calcite is $2,710 \mathrm{~kg} / \mathrm{m}^{3}, M_{\text {mineral }}$ is molecular mass of calcite $(0.1001 \mathrm{~kg} / \mathrm{mol})$, and $f$ is the percentage of calcite.

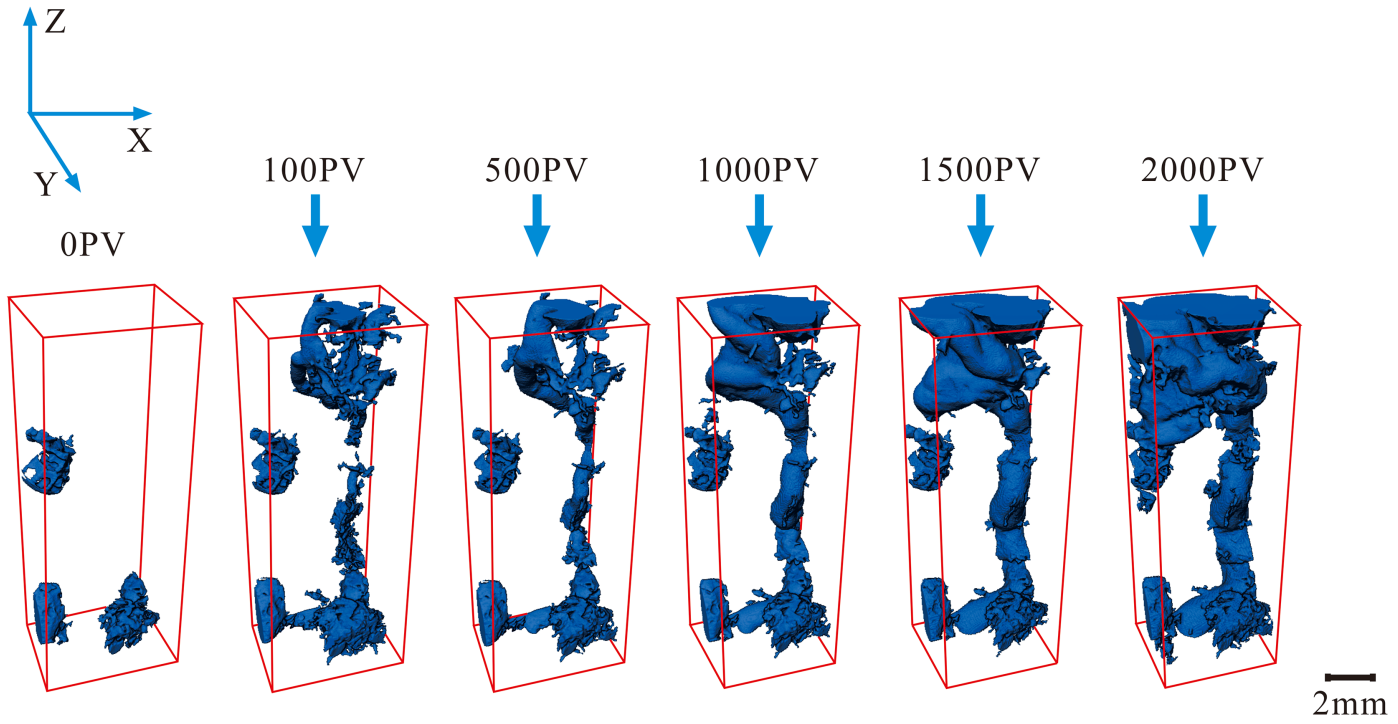

Figure 9. Three-dimensional visualizations $\left(250 \times 250 \times 800\right.$ voxels $\left.=5.29 \mathrm{~mm} \times 5.29 \mathrm{~mm} \times 16.91 \mathrm{~mm}=472.37 \mathrm{~mm}^{3}\right)$ of the pore space in the vuggy limestone. The arrow represents the direction of $\mathrm{CO}_{2}$ acidified brine injection. 


\section{Homogeneous sample A}

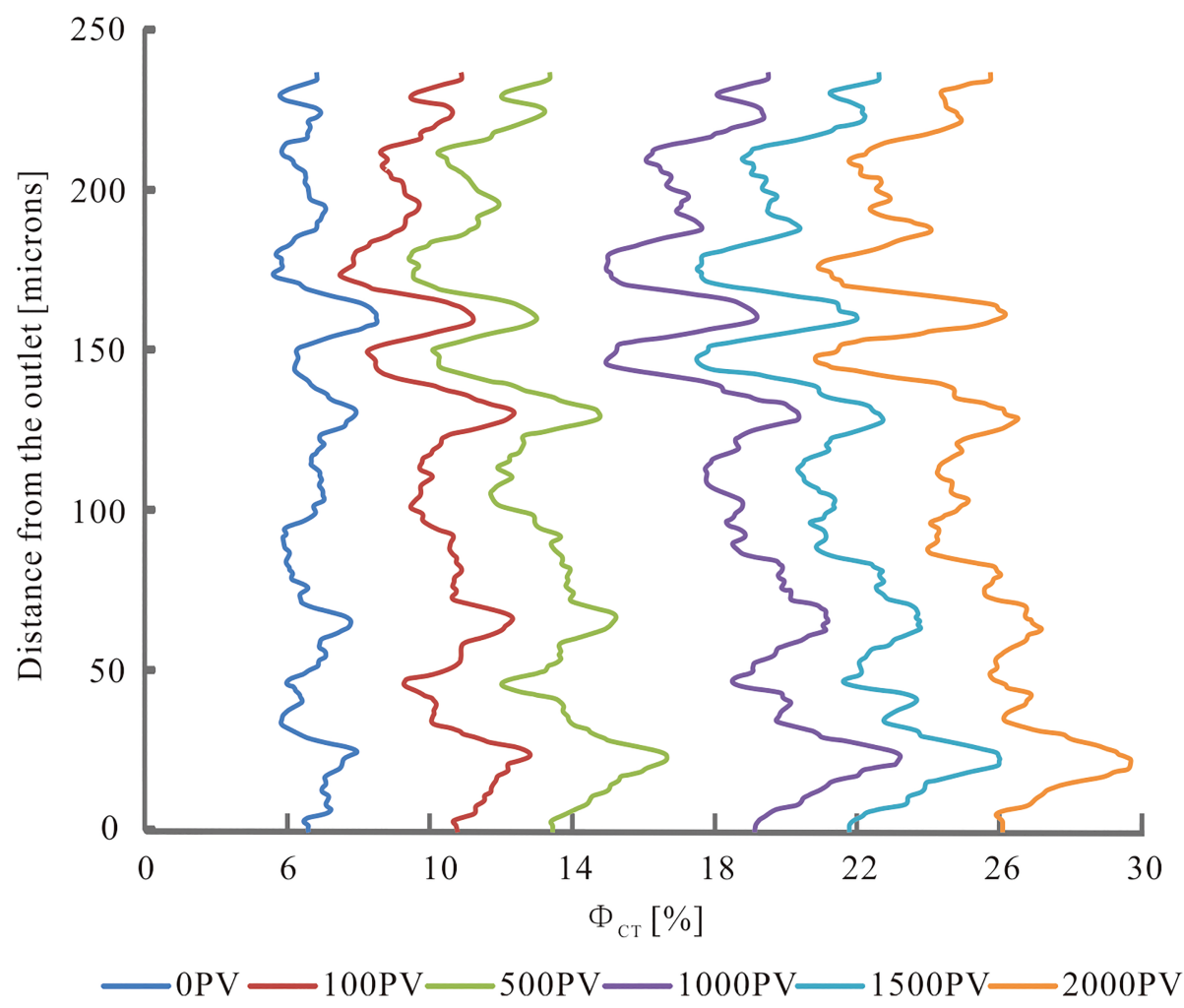

Figure 10. Relationship between slice-averaged porosity and distance from the sample outlet, homogeneous Sample A.

Effective reaction rate is the reaction rate in core with irregular pore, rather than the intrinsic reaction rate under well-mixed conditions (Al-Khulaifi et al., 2017). Equation 9 thus captures an effective reaction rate $(r-$ eff) of the mineral dissolution, where $\Delta t$ is the time interval between scans, and the mineral volume changes $(\Delta \phi \mathrm{CT})$ were determined by segmenting consecutively scanned $\mathrm{CT}$ images. We assume that all the surface area contributes to the reaction with $\mathrm{CO}_{2}$ saturated brine although such surface area may be lower than the real due to the resolution limitation:

$$
r_{e f f}=\frac{\rho_{\text {mineral }}\left(1-\phi_{C T}\right)}{M_{\text {mineral }} S} \frac{\Delta \phi_{C T}}{\Delta t}
$$

\section{Results and Discussion}

\subsection{Pore-Scale Limestone Dissolution}

\subsubsection{Dissolution of Homogeneous Carbonate Rock}

In the homogeneous carbonate (blue box in Figure 4, $21.14 \mu \mathrm{m}$ ), clearly, a single channel formed gradually. At higher resolution $(4.26 \mu \mathrm{m})$, it could be observed that circular particles dissolved and pore space originally disconnected in 2-D plane became connected. The new pore space was formed adjacent to the original effective pore space, consistent with Lebedev et al. (2017) who showed that acidified brine partially flows through the high permeability part of the sample. However, Menke et al. (2017) found a uniform dissolution mechanism and several flow paths developed there throughout the rock due to the continuous exposure of the entire rock surface to the reactive fluid. Other areas of Sample A also dissolved, although they were spatially smaller but larger in number. This discrepancy was caused by the comparatively lower homogeneity of our sample, while uniform dissolution occurs only when grains are highly sorted and rounded. 


\section{Fractured sample B}

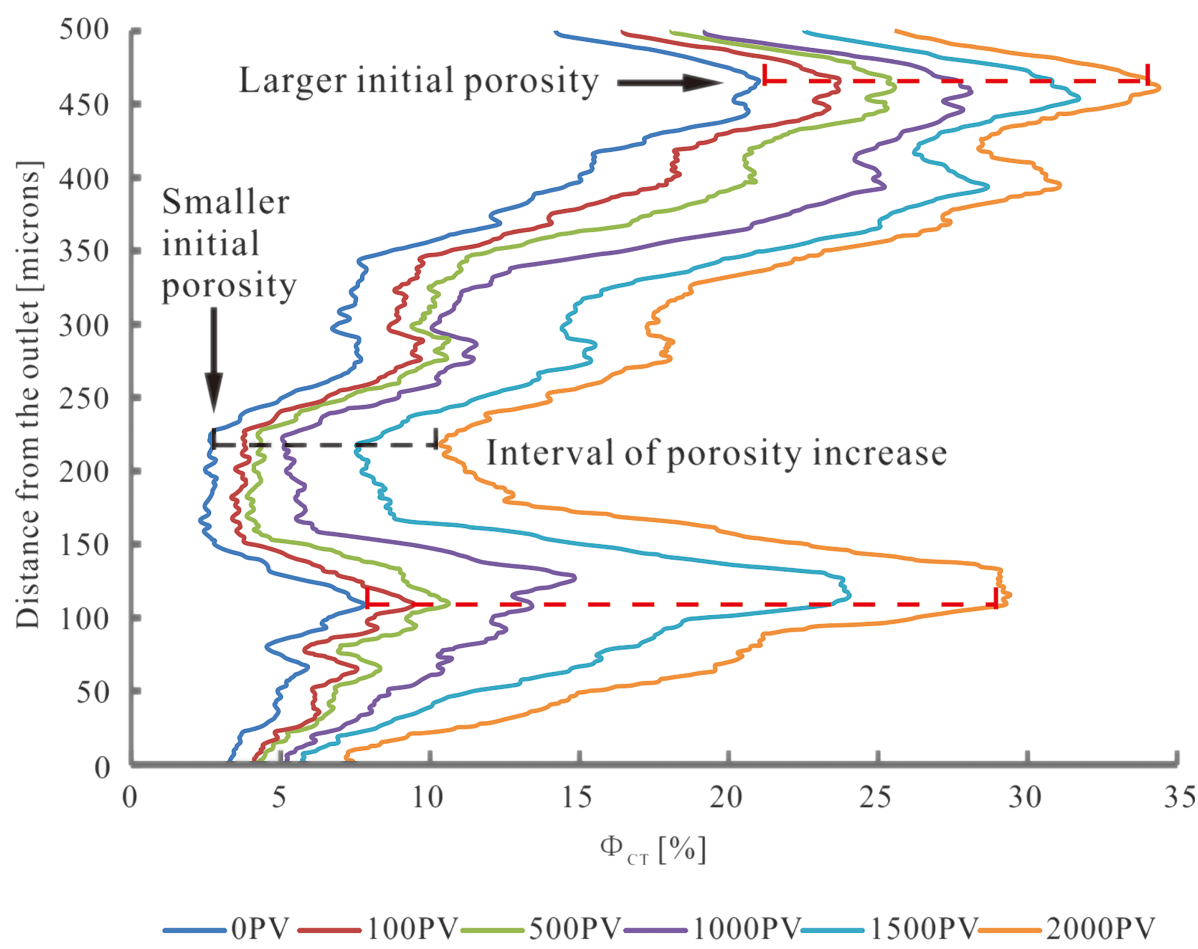

Figure 11. Relationship between slice-averaged porosity and distance from the sample outlet, homogeneous Sample B.

\subsubsection{Dissolution of Fractured Carbonate Rock}

The fractured carbonate rock showed a distinctly different response. Clearly, the acidic brine flowed mainly through the fractures as expected, and dissolution thus occurred at the fracture walls, thus increasing the fracture aperture, Figure 5. Furthermore, some particles consisting of calcite crystals on the inner wall of the fractures were dissolved in the flooding process (red part of 2,000 and 1,500 PV in Figure 5). The inner wall of the fracture was also smoothed, while fracture aperture increased. At the same time, we also observed an interesting phenomenon as indicated by the red circles; that is, particles appeared in the fractures, apparently flowing downstream which further proves that the flow channel of the $\mathrm{CO}_{2}$ acidified brine is confined to the main fractures.

\subsubsection{Dissolution of Vuggy Carbonate Rock}

Initially, this rock contained disconnected vugs; after injecting $100 \mathrm{PV}$ of the acidic brine, one of these vugs enlarged (shown in the red circle in Figure 6) and eventually formed an irregularly shaped hole in the center of the visual field. Unlike dissolution in the homogeneous carbonate, dissolution proceeded in four directions. This is clearly related to the heterogeneous pore structure and chemical composition (this rock contains $24 \mathrm{wt} \%$ anhydrite, Table 1). Notably, the vug only grew into the calcite matrix (gray), but not into the anhydrite (white/light gray), during further injection of 1,500-2000 PV of acidic brine. Although anhydrite slightly dissolves in water at $50{ }^{\circ} \mathrm{C}$, calcite reacts with acid to form $\mathrm{Ca}^{2+}$, which inhibits the dissolution of anhydrite. Therefore, we observed on 2-D slices that anhydrite was almost insoluble. The above described effect was, however, not observed in the high-resolution image $(4.26 \mu \mathrm{m})$, as it occurred outside the field of view. This indicates that dissolution in vuggy carbonate is heterogeneous and localized, and thus, dissolution is strongly confined spatially, which is distinctly different to dissolution in homogeneous carbonate, see above. We conclude that areas outside the reactive vug are hardly affected by the reactive fluid.

\subsection{Preferential Channel Growth and Porosity Analysis}

In order to further quantify the dissolution induced changes in the pore morphology, we analyzed the 3-D spatial distribution of the largest flow channels and calculated dynamic permeabilities on the segmented images. 


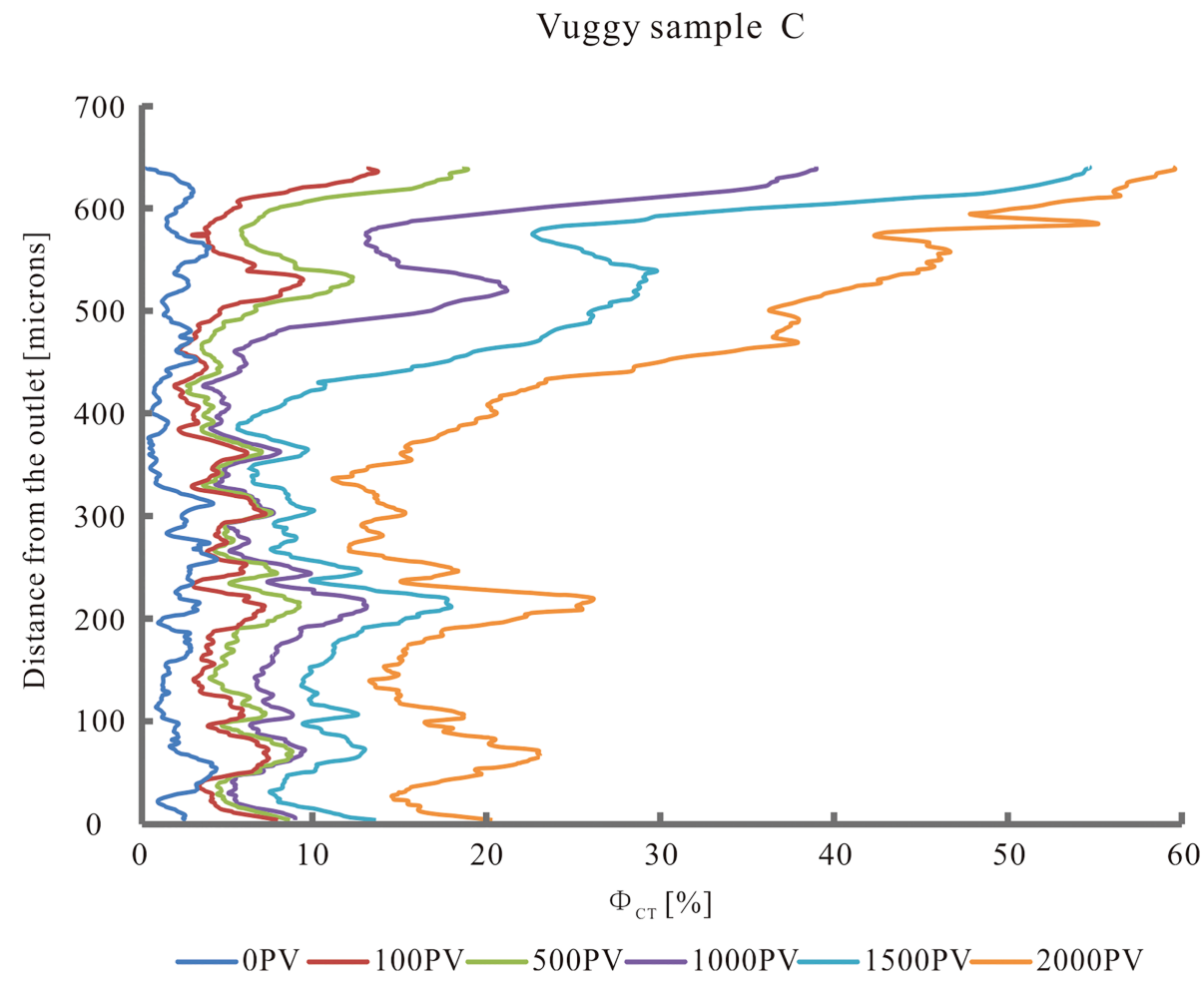

Figure 12. Relationship between slice-averaged porosity and distance from the sample outlet, homogeneous Sample C.

\subsubsection{Analysis of the Connected 3-D Pore Space}

Figure 7 shows 3-D visualizations of the pores with a volume larger than $10^{8} \mu \mathrm{m}^{3}$ for the homogeneous sample at different dissolution stages. A main channel formed in the $X Y$ and $Y Z$ directions, consistent with Luquot and Gouze (2009) and Al-Khulaifi et al. (2018). In addition, there were many branched channels around the main channel, which grew continuously until 1,500 PV of acid were injected, afterward these branches did almost not grow any longer. The reason is that the main channel became the dominant path of acid flow, which is confirmed by the permeability analysis in section 3.3: The permeability at 2,000 PV is below the power law curve; that is, the trend of permeability growth slowed down, indicating that the reactive fluid was confined to the dominant channel and did not react with other particles.

In the fractured sample, the original two fractures were clearly the preferential flow channels as expected, these fractures constantly widened during acid injection, while small branched channels developed at the outlet, Figure 8. However, the overall structure and shape of the pore space remained unchanged; thus, regions outside fractures hardly reacted with the $\mathrm{CO}_{2}$ acidified brine, consistent with the phenomena described in section 3.1.2. Note that $\mathrm{CO}_{2}$ acidified brine can weaken the limestone matrix mechanically (Lebedev et al., 2017). In fractured carbonate rock, $\mathrm{CO}_{2}$ acidified brine chose the original fractures as the preferential flow channels, so the original fractures are easier to be dissolved. We conclude that $\mathrm{CO}_{2}$ injection near geological faults increases the probability that faults will be reactivated.

Figure 9 shows the effective 3-D pore space $\left(21.14 \mu \mathrm{m}\right.$ resolution; pore sizes larger than $10^{9} \mu \mathrm{m}^{3}$ are shown) for the vuggy carbonate rock. Initially there were three large disconnected vugs, which connected after injection of 2,000 PV of the acidic brine. In contrast to the homogeneous sample, not many branched flow channels developed around this main flow channel. In fact, vuggy carbonate rock is highly heterogeneous; thus, our experimental result extends the application scope of the single channel dissolution pattern proposed by Menke et al. (2017).

\subsubsection{Porosity Changes and Dissolved Volume}

Figures 10-12 depict the average porosity over each 2-D slice along the flow direction for the three carbonate rock samples. For homogeneous carbonate rock (Figure 10), the majority of the porosity increase occurred 


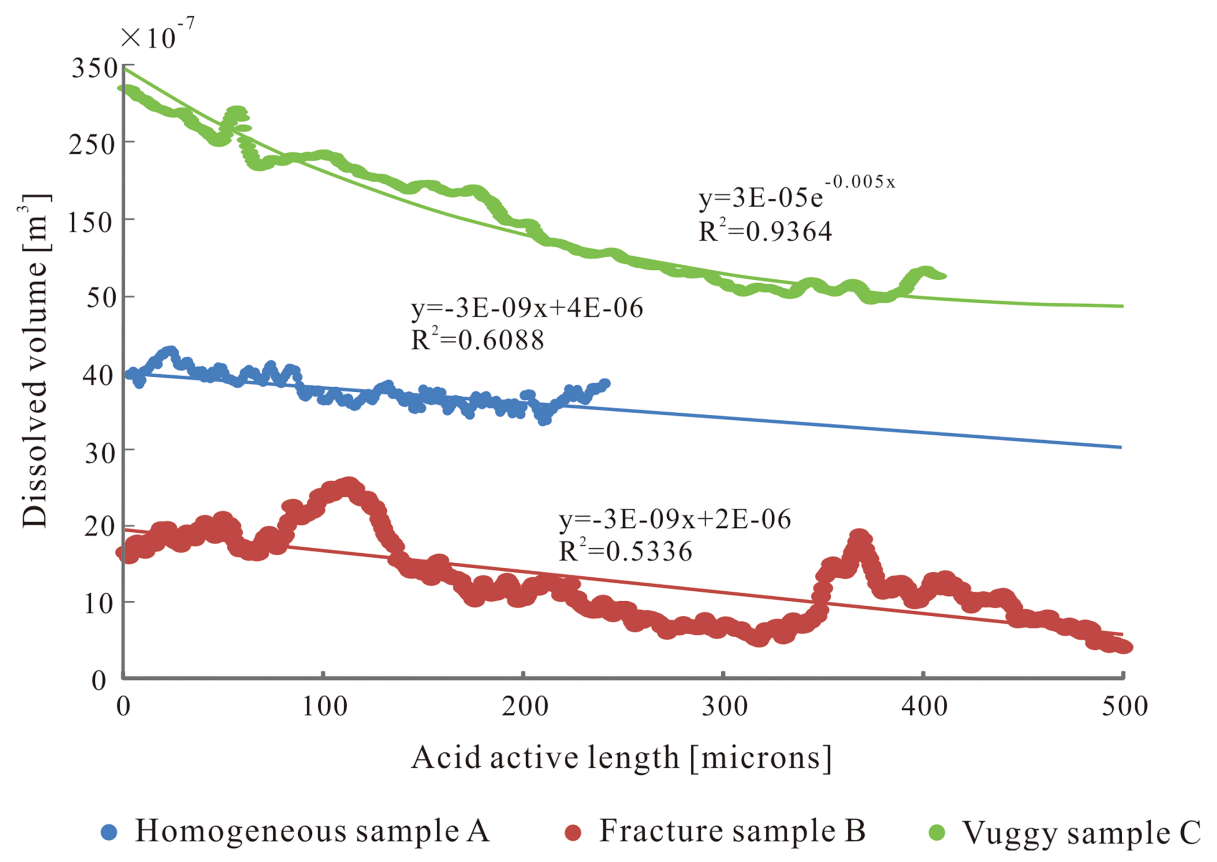

Figure 13. Dissolved volume fraction calculated from micro-CT images versus core length. The dissolved volume of Sample A and C is calculated at 2,000 PV and that of Sample B at 500 PV.

during the first 1,000 PV injected, and porosity increased uniformly over the length of the core. However, for fractured carbonate rock (Figure 11), the porosity increase was lower where the initial porosity was low, and stronger where initial porosity was large. The porosity increase in vuggy carbonate rock was mainly localized in the entrance area (Figure 12) and increased continuously with injection time, consistent with the observations in Figure 9. We conclude that more attention should be paid to the damage around the

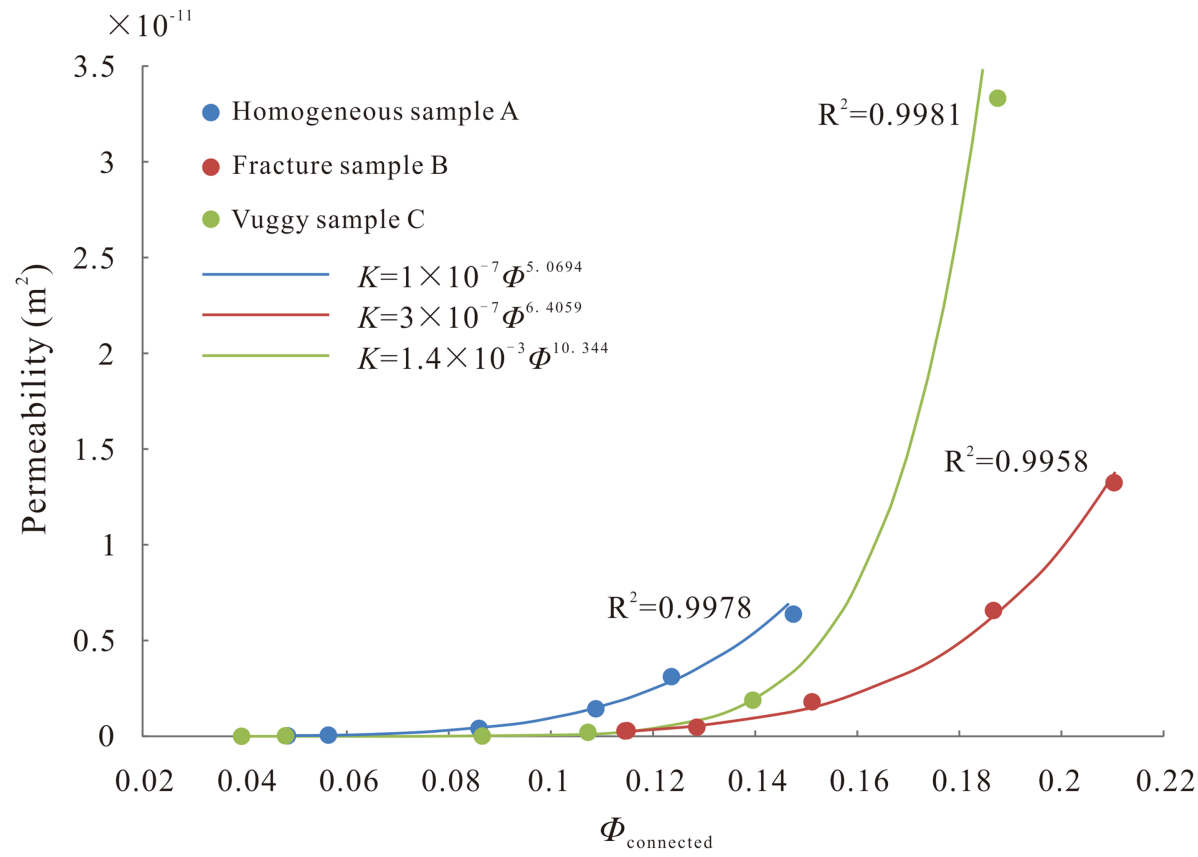

Figure 14. The power law relationships between permeability and connected porosity for the different samples studied. The porosity-permeability increase is dependent on dissolution pattern. 
Table 2

Parameters for All the Samples Over the Full Course of Experiments

\begin{tabular}{|c|c|c|c|c|c|c|c|}
\hline Sample & Injected pore volume & $\phi_{\mathrm{CT}}$ & $\mathrm{S}\left(\mathrm{m}^{-1}\right)$ & $\mathrm{L}(\mathrm{m})$ & $\mathrm{Pe}$ & $D a\left(10^{-5}\right)$ & $r_{e f f}\left(\mathrm{~mol} / \mathrm{m}^{2} \mathrm{~s}\right)$ \\
\hline \multirow[t]{6}{*}{ A } & 0 & 0.068 & 28,082 & $1.12 \times 10^{-4}$ & 298 & 3.07 & 0 \\
\hline & 100 & 0.096 & 24,293 & $1.29 \times 10^{-4}$ & 244 & 3.52 & $5.23 \times 10^{-6}$ \\
\hline & 500 & 0.131 & 19,744 & $1.59 \times 10^{-4}$ & 220 & 4.35 & $1.58 \times 10^{-6}$ \\
\hline & 1,000 & 0.189 & 17,137 & $1.83 \times 10^{-4}$ & 176 & 5.96 & $1.41 \times 10^{-6}$ \\
\hline & 1,500 & 0.219 & 15,544 & $2.02 \times 10^{-4}$ & 167 & 7.57 & $5.16 \times 10^{-7}$ \\
\hline & 2,000 & 0.253 & 13,836 & $2.27 \times 10^{-4}$ & 162 & 9.15 & $4.71 \times 10^{-7}$ \\
\hline \multirow[t]{6}{*}{ B } & 0 & 0.122 & 6,986 & $4.50 \times 10^{-4}$ & 669 & 9.99 & 0 \\
\hline & 100 & 0.131 & 6,773 & $4.64 \times 10^{-4}$ & 642 & 10.84 & $3.65 \times 10^{-6}$ \\
\hline & 500 & 0.144 & 6,283 & $5.00 \times 10^{-4}$ & 630 & 12.09 & $1.12 \times 10^{-6}$ \\
\hline & 1,000 & 0.168 & 5,778 & $5.44 \times 10^{-4}$ & 587 & 14.52 & $1.09 \times 10^{-6}$ \\
\hline & 1,500 & 0.203 & 4,956 & $6.34 \times 10^{-4}$ & 566 & 18.31 & $1.18 \times 10^{-6}$ \\
\hline & 2,000 & 0.229 & 4,574 & $6.87 \times 10^{-4}$ & 544 & 21.35 & $6.92 \times 10^{-7}$ \\
\hline \multirow[t]{6}{*}{ C } & 0 & 0.079 & 17,863 & $1.76 \times 10^{-4}$ & 404 & 12.79 & 0 \\
\hline & 100 & 0.108 & 15,856 & $1.98 \times 10^{-4}$ & 333 & 13.87 & $7.25 \times 10^{-6}$ \\
\hline & 500 & 0.127 & 13,802 & $2.28 \times 10^{-4}$ & 325 & 15.48 & $1.07 \times 10^{-6}$ \\
\hline & 1,000 & 0.151 & 12,132 & $2.59 \times 10^{-4}$ & 311 & 18.58 & $7.47 \times 10^{-7}$ \\
\hline & 1,500 & 0.18 & 10,909 & $2.88 \times 10^{-4}$ & 290 & 23.44 & $6.46 \times 10^{-7}$ \\
\hline & 2,000 & 0.228 & 9,318 & $3.37 \times 10^{-4}$ & 268 & 27.33 & $8.84 \times 10^{-7}$ \\
\hline
\end{tabular}

wellbore when injecting $\mathrm{CO}_{2}$ into vuggy carbonate reservoirs, especially considering that the mechanical properties of limestone matrix are significantly weakened by $\mathrm{CO}_{2}$ acidified brine.

These dissolution effects were further quantified; thus we analyzed the relationship between the dissolved volume and core length (Figure 13). These functions (at 2,000 PV) were linear for Sample A (homogeneous) and exponentially decreasing trend for Sample C (vuggy), while dissolved volume of Sample A varied little with core length, and dissolution was almost uniform throughout the core.

For fractured Sample B, the dissolved volume at 500 PV was a linear decay (Figure 13), which helps us to find a rule: Dissolution occurred mainly near the entrance when $500 \mathrm{PV}$ reactive fluid was injected. Note that the dissolved volume at 2,000 PV was also analyzed, but there was no obvious correlation between it and core length. This irrelevancy was due to the rapid increase of the dissolved volume near the outlet in the later stage of dissolution (e.g., in Figure 11 the yellow curve of 2,000 PV, $100 \mu \mathrm{m}$ from the outlet, you also find that the initial porosity of this location is larger). With the increase of $\mathrm{CO}_{2}$ injection, the larger the initial porosity, the easier the dissolution occurred. Therefore, the dissolution of fractured carbonate rocks is not simply concentrated in the entrance area but related to initial porosity.

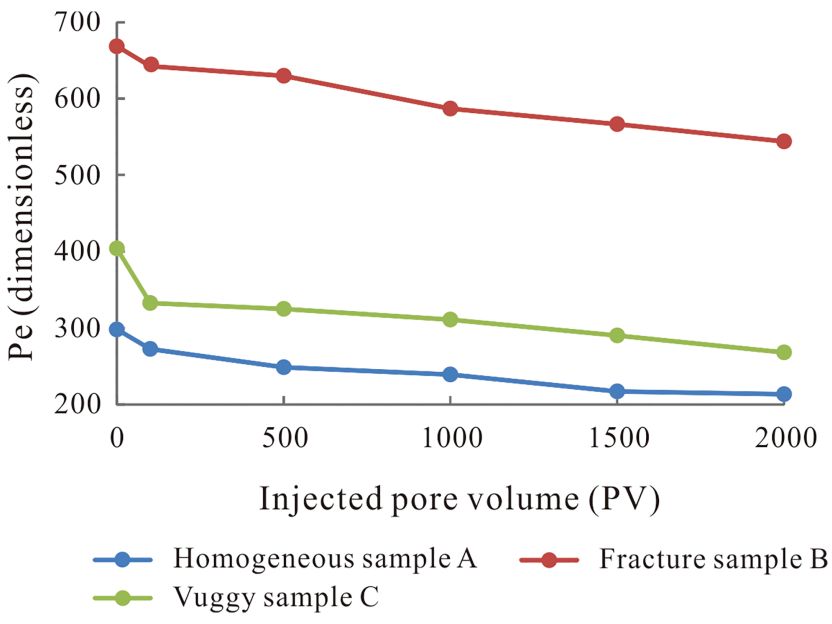

Figure 15. Péclet number $(P e)$ versus the injected pore volumes.
This porosity evolution and dissolution rates can be explained by a higher reactive surface area in vuggy sample than in the homogeneous one. In fact, the initial permeability of Sample A was higher than for Sample C. This mean that the connectivity was better in the homogeneous sample, which promotes the localization of the dissolution in the initial main branches, whereas in Sample C dissolution reaction should connect the vuggy pore together to increase the permeability and the dissolution rate is thus higher.

\subsection{Porosity-Permeability Relationship}

Time-dependent porosity-permeability relationships for the three samples were obtained via LBM (see section 2.2), Figure 14. These relationships can be fitted well ( $R^{2}$ of all samples is above 0.99$)$ with a power law $(K=a$ $\phi_{\text {connected }}^{b}$, where $K$ is the dynamic permeability, $\phi_{\text {connected }}$ is the porosity connected along the flow direction, $a$ is a constant, and $b$ is the power law exponent). 


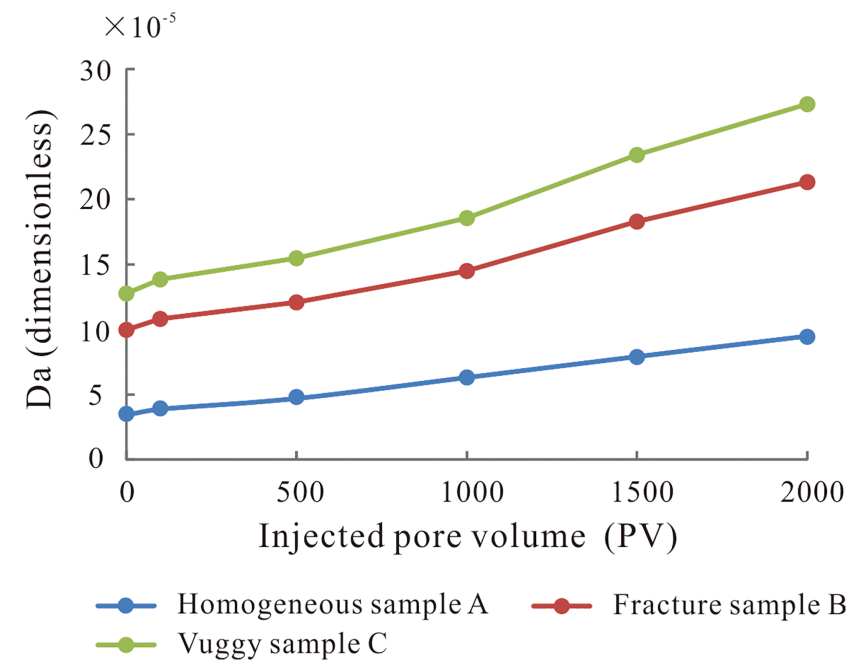

Figure 16. Damköhler number $(D a)$ versus injected pore volumes.
The power law exponents of (homogeneous) Sample A and (fractured) Sample B were 5.0694 and 6.4059, respectively, and thus significantly smaller than that of the vuggy Sample C (10.344). This indicates that the permeability of Sample C, with the lowest connectivity, increased fastest. We note that the initial (connected) porosity of Sample C was only 3.94\%, and the corresponding initial permeability was only $3.55 \times 10^{-18} \mathrm{~m}^{2}$; however, the growth of the preferential channel connected the disconnected pores as shown in Figure 9, and a small increase in porosity led to a dramatic permeability increase. As discussed later, this is caused by the dissolution pattern (single channel growth in highly heterogeneous rocks). Previous studies indicated that single channel formation can completely dominate permeability (Al-Khulaifi et al., 2019; Siddiqui et al., 2006). Contrarily, homogeneous Sample A and fractured Sample B showed lower exponents, indicating a slower permeability increase compared to single channel formation. We note that the permeabilities at 2,000 PV distributed below the fitting curves for all the samples, thus the increasing trend of permeability slowed down gradually in the later stage of dissolution. This is consistent with the permeability study: There is less reaction between acidified brine and rock particles after preferential channel is formed, which is manifested in a lower exponent (Al-Khulaifi et al., 2018; Luquot \& Gouze, 2009; Menke et al., 2015; Smith et al., 2017).

\subsection{Dynamic Péclet and Damköhler Number and Effective Reaction Rates}

$\mathrm{Pe}$ (the ratio of advection rate to diffusion rate) was calculated using the flow rate of $0.1 \mathrm{~mL} / \mathrm{min}$ and the specific surface area obtained from the segmented images for the three samples (Table 2). In all experiments a high Péclet number prevailed; thus, fresh $\mathrm{CO}_{2}$-acidized brine was readily available throughout the core since the spatially averaged advection rate was much higher than the $\mathrm{H}^{+}$diffusion rate. Table 2 also contains $D a$ and $r_{\text {eff }}$ derived from porosity changes at different dissolution stages. In all experiments, the ratio of reaction rate to mass transfer rate $(D a)$ was significantly lower than 1 , which indicates that the reaction rate was relatively slow when compared to both, the diffusion and advection rate. Furthermore, the initial effective reaction rate of vuggy Sample C was the highest, while it was lowest for the fractured Sample B.

Figure 15 depicts the evolution of Péclet numbers. As expected, $P e$ of Sample A (homogeneous, with high specific surface area) was lowest, while that of Sample B (fractured, with the lowest specific surface area) was the highest. For all samples, Pe decreased rapidly initially, but more gradually after $100 \mathrm{PV}$ of injection. This indicates that there was a competition between preferential flow paths during channel formation, which led to an advection-dominated transport in more pore space. Once the main channels were formed, the majority of the acidic brine flowed through them, and as a consequence the matrix pore space (outside the preferential channels) was dominated by diffusion. Furthermore, the high Pe number in Sample B indicates that advective transport in the fractured sample was strongest. Conversely, Pe of Samples A and C were smaller, which indicates a relatively strong impact of diffusion. The fluid is relatively stationary in the area where dissolution occurs, and there are obvious diffusive restrictions on transport and reaction (Menke et al., 2017).

$D a$ was always significantly higher than 1 , and $D a$ increased with the number of PV injected (Figure 16), consistent with the porosity increase, compare equation 7. Da of homogeneous Sample A was always lower than that of the other two samples, which indicates that the reaction rate is slower than the advection rate, consistent with homogeneous dissolution. Note that increasing $\mathrm{Da}$ reflects more nonuniform dissolution (Golfier et al., 2002), which is consistent with the preferential channel growth in homogeneous carbonate rock, compare section 3.2.1. With the increase of the pore volume, the competitive advantage of the preferential flow

Figure 17. Effective reaction rates $\left(r_{\text {eff }}\right)$ versus injected pore volume. 

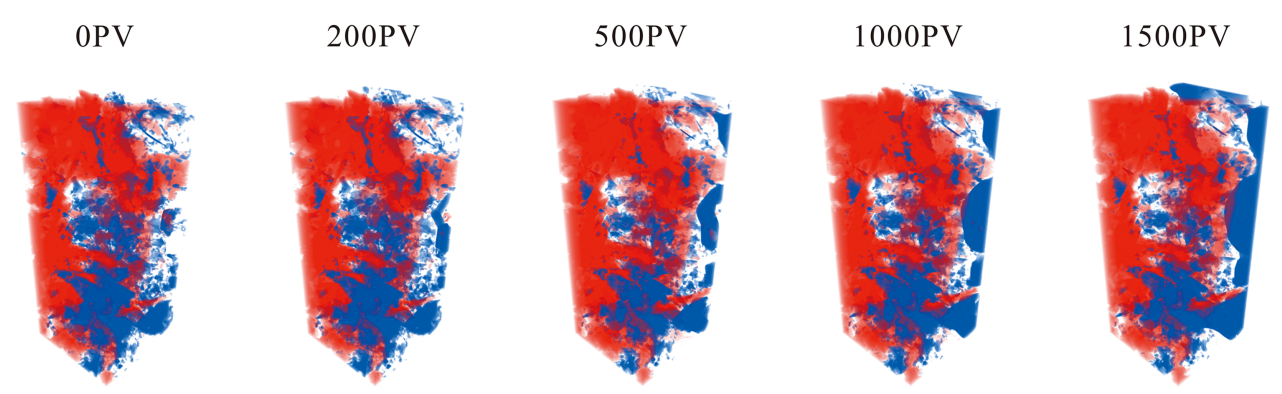

Shielded calcite

$2 \mathrm{~mm}$ and pore space

Figure 18. Three-dimensional view of anhydrite (red) and pore space (blue) of vuggy Sample C. The blank part filled with calcite.

channel became more and more significant in the homogeneous Sample A; on the contrary, the branched channels hardly grew after 1,500 PV injection. For Sample B and Sample C, their Da remained at a high level, indicating that the dissolution is nonuniform from beginning to end, and the preferential channels dominate the flow in the early stage of dissolution.

The effective reaction rate $\left(r_{\text {eff }}\right)$ measured on the segmented images using equation 9 decreased with time at constant experimental conditions (Figure 17). We conclude that the preferential flow channels control the flow and lead to the decrease of the $r_{\text {eff. }}$ Because the majority of acidic liquid passed through the center of preferential channels and reacted only with the channel walls without touching or reacting with other rock grains (Menke et al., 2017). In addition, the initial effective reaction rate of fractured Sample B was the lowest. Lower $r_{\text {eff }}$ indicates that the reactive fluid cannot fully react with the rock grains. On the other hand, it can be understood that the fracture controls the flow from the beginning. Note that Al-Khulaifi et al. (2019) discussed the effect of chemical heterogeneity (they used a sample consisting of calcite and dolomite) on the effective reaction rate, and pointed out that the proximity of minerals to preferential flow channels determines the effective reaction rate and calcite was shielded by dolomite once the main flow channel formed. As our Sample C is also chemically heterogeneous (Table 1), we also extracted the spatial distribution of anhydrite and pore of vuggy sample during the dissolution process. Figure 18 represented only the area where the anhydrite is distributed, this is not representative of the entire sample (according to the results of mineral content analysis as shown in Table 1, the calcite content is more than 3 times the anhydrite content). Red represents anhydrite, blue is pore space, and the blank part is the filled calcite. Clearly, the anhydrite (on the left) shielded calcite from reacting, causing the preferential flow channel to localize on the right. Since the anhydrite hardly reacted

\section{Pe (dimensionless)}

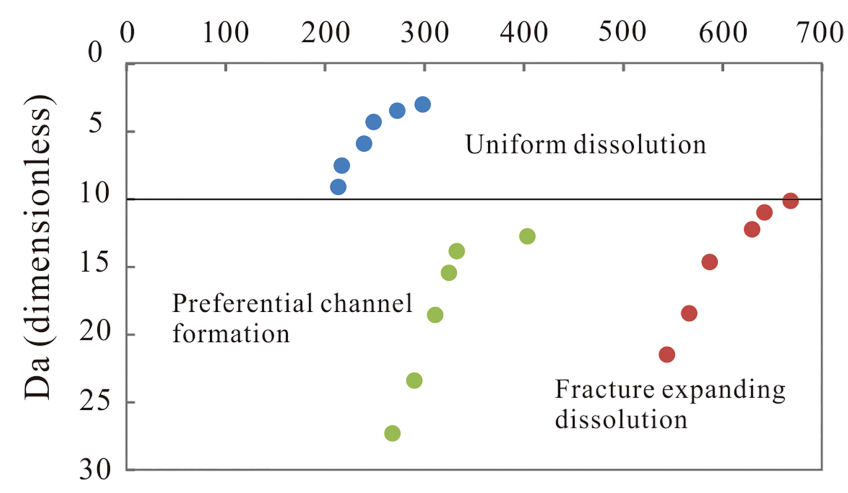

$\times 10^{-5}$

- Homogeneous sample A

- Vuggy sample C

- Fracture sample B

Figure 19. $P e-D a$ distribution diagram versus injected pore volume. with the $\mathrm{CO}_{2}$ acidified brine, the growth direction of the main flow channel changed four times from 2-D slices. Furthermore, we speculate that the shielding effect of anhydrite on calcite will limit the full core effective reaction rates.

Different dissolution patterns correspond to different $P e-D a$ combinations. It is obvious that the $P e-D a$ distribution of three samples were different, and clustering of points was apparent, Figure 19. The $P e-D a$ points were clustered around their basic dissolution pattern, but for all sets, $P e$ increased while $D a$ decreased with increasing PV injected, consistent with Al-Khulaifi et al. (2017), Al-Khulaifi et al. (2018), Menke et al. (2016), Menke et al. (2017), and Menke et al. (2018). Golfier et al. (2002) provided the $P e-D a$ distribution diagram for several dissolution patterns and found that uniform dissolution with the smaller the Damköhler number. Preferential channel formation and dissolution fracture expansion can be found in the range $10^{2} \leq P e \leq 10^{3}$. The demarcation line between uniform and nonuniform dissolution is $D a=10^{-4}$ for our three sets of experiments, which is different with Golfier's demarkation line (at $D a \leq 8 \times 10^{-4}$; which was developed based on 2-D flat Hele-Shaw cells). 


\begin{tabular}{|l|lll|}
\hline \multicolumn{1}{|c|}{ (a) } \\
Dissolution
\end{tabular}

Figure 20. Conceptualized channel growth versus time during (a) uniform dissolution, (b) fracture expanding dissolution, and (c) preferential channel formation. Rock matrix (gray) is dissolved in advection-dominated regions (red arrows).

Note that the experimental results of Al-Khulaifi et al. (2018), Menke et al. (2017), and Menke et al. (2016) show that the $D a$ value were distributed between $1.88 \times 10^{-5}$ and $9.28 \times 10^{-5}$ in the case of nonuniform dissolution, it is also beyond the range of nonuniform dissolution Golfier et al. (2002) offers. Actually, they simulated dissolution based on a simple 2-D flat model; while our study is based on real digital cores. Furthermore, a salt-filled transparent Hele-Shaw cell they used in experiment is different with natural limestones. We thus conclude that the range of Damköhler number in the same dissolution pattern is not constant, which is closely related to the complexity of pore geometry. As the complexity of the pore geometry increases, dissolution tends to be nonuniform.

\subsection{Dissolution Pattern of Carbonate Rocks With Different Initial Pore Structure}

The dissolution process for the three limestone samples were conventionalized in Figure 20. During uniform dissolution, the reactive fluid passes through pore space uniformly, thus most of the carbonate grains encounter and react with reactive fluid and eventually form multiple channels, rather than a single one. Such uniform dissolution can only occur when the pore structure of the rock is very uniform, that is, the size of the grains is similar and the degree of sphericity is very high (Menke et al., 2017). However, reservoir rock is not highly homogeneous. Furthermore, the preferential channel formed in Sample A is different from those formed in Samples B and C, where many surrounding branching channels were observed. In 
fractured carbonate rock (Figure 20b), the reactive fluid flows through the original fractures so that the fractures extend and widen during dissolution, while the region far from the fractures hardly react. In a highly heterogeneous vuggy carbonate rock, the majority of the injected reactive fluid passes through the center of a fast flow path (largest vug); thus, it mainly reacts with the grains on the channel wall and a single preferential channel is formed. Moreover, the vugs around the preferential channel are further widened as they are also somewhat exposed to the acid.

\section{Conclusions}

The physical heterogeneity has an important influence on limestone dissolution. Understanding the dissolution patterns of carbonate rocks with different pore structures can be applied to reservoir modeling and prediction of dissolution process. Based on a series of parametric analysis of micro-CT images, dissolution patterns of three different limestones were examined. Two-dimensional slices and 3-D images at different dissolution stages reveal that preferential channels were formed (or widened in case of fractures) throughout the whole core. Formation time and shape of the channels depended on the initial pore structure of the rock. These results were further quantified and compared with literature data. Following conclusions were drawn from the study:

1. The relatively homogeneous sample formed a large number of branched channels around a preferential main flow channel throughout the whole sample. However, after 1,500 PV of acidic brine were injected, the branched channels hardly grew, with the preferential channel now discharging most of the reactive fluid.

2. Fracture aperture increased continuously in the fractured carbonate rock, while the fracture wall smoothened. In addition, particles migrating downstream were observed, prove that the fracture is the main flow path of the acidic brine. However, the overall structure and shape of the pore space remained unchanged. Considering the weakening of limestone matrix by $\mathrm{CO}_{2}$ acidified brine, the initial fractures were more likely to be dissolved. We should pay attention to reservoir instability caused by the reactivating of geological faults when injecting $\mathrm{CO}_{2}$ near geological faults.

3. Channel growth was more complex in the vuggy limestone, while vugs grew in four directions successively. This growth was anisotropic in presence of anhydrite, which impeded dissolution (due to its lower chemical reactivity). In addition, formation of only one preferential channel was observed.

4. Porosity increased uniformly during the dissolution in the homogeneous sample, while porosity increase in the fractured sample was localized within the fractures themselves. In the vuggy sample, dissolution was dominant in the inlet area. We should pay more attention to wellbore instability caused by the weakening of near-wellbore matrix when injecting $\mathrm{CO}_{2}$ into vuggy carbonate reservoirs.

5. The formation of a single preferential channel in the vuggy carbonate resulted in a sharp increase in permeability, which was manifested in the highest porosity-permeability power law exponent (10.344). In contrast in fractured and homogeneous carbonate, this exponent was smaller in uniform and fracture expanding dissolution patterns, permeability increased relatively slowly there.

6. We conclude that during channel formation, there is a competition between flow paths, which leads to an advection-dominated transport in more pore space. Once the preferential channels formed, the relative importance of diffusion became greater. This advection effect was strongest in the fractured sample, which had the highest Péclet number. Conversely, Pe of homogeneous (Sample A) and vuggy (Sample C) rocks were smaller, thus the fluid was relatively stationary in the area where dissolution occurred and there were diffusive restrictions on transport and reaction. The Damköhler number of homogeneous carbonate rock was always lower than that of the other two samples, which is required for homogeneous dissolution. The $D a$ increase reflected the dissolution transformation from uniform to nonuniform. With the increase of the injected pore volume, the competitive advantage of the preferential channel became obvious. For fractured (Sample B) and vuggy (Sample C) rocks, Da remained high, indicating that the dissolution was always nonuniform.

7. Once preferential channels formed, the majority of reactive fluid passed through the center of these channels, which limited the effective reaction rate between the reactive fluid and the rock itself. Furthermore, the effective reaction rate of the fractured Sample B was the lowest initially, which illustrates that the fracture controlled the flow from the beginning. 
8. The three dissolution patterns were analyzed in terms of their $P e-D a$ distributions. The boundary between uniform and nonuniform dissolution was identified as $D a=10^{-4}$. However, the dissolution tends to be nonuniform as the pore geometry complexity increases.

\section{Acknowledgments}

We acknowledge the following financial support: the National Natural Science Foundation of China (51674280, 51490654, 51722406, and 61573018), Shandong Provincial Natural Science Foundation (ZR2019JQ21 and JQ201808), Key Research and Development Plan of Shandong Province (2018GSF116009), the Fundamental Research Funds for the Central Universities (17CX05003 and 18CX02031A), and Program for Changjiang Scholars and Innovative Research Team in University (IRT_16R69). The segmented images used in this study can be downloaded from https://github.com/ Yongfei-Yang/-Segmented-images website.

\section{References}

Al-Khulaifi, Y., Lin, Q., Blunt, M. J., \& Bijeljic, B. (2017). Reaction rates in chemically heterogeneous rock: Coupled impact of structure and flow properties studied by X-ray microtomography. Environmental Science \& Technology, 51(7), 4108-4116. https://doi.org/10.1021/acs. est.6b06224

Al-Khulaifi, Y., Lin, Q., Blunt, M. J., \& Bijeljic, B. (2018). Reservoir-condition pore-scale imaging of dolomite reaction with supercritical $\mathrm{CO}_{2}$ acidified brine: Effect of pore-structure on reaction rate using velocity distribution analysis. International Journal of Greenhouse Gas Control, 68, 99-111. https://doi.org/10.1016/j.ijggc.2017.11.011

Al-Khulaifi, Y., Lin, Q., Blunt, M. J., \& Bijeljic, B. (2019). Pore-scale dissolution by $\mathrm{CO}_{2}$ saturated brine in a multimineral carbonate at reservoir conditions: Impact of physical and chemical heterogeneity. Water Resources Research, 55, 3171-3193. https://doi.org/10.1029/ 2018wr024137

Andreani, M., Gouze, P., Luquot, L., \& Jouanna, P. (2008). Changes in seal capacity of fractured claystone caprocks induced by dissolved and gaseous $\mathrm{CO}_{2}$ seepage. Geophysical Research Letters, 35, L14404. https://doi.org/10.1029/2008gl034467

Arbogast, T., Brunson, D. S., Bryant, S. L., \& Jennings, J. W. (2004). A preliminary computational investigation of a macro-model for vuggy porous media. Developments in Water Science, 55, 267-278. https://doi.org/10.1016/S0167-5648(04)80056-X

Bachu, S. (2000). Sequestration of $\mathrm{CO}_{2}$ in geological media: Criteria and approach for site selection in response to climate change. Energy Conversion and Management, 41(9), 953-970. https://doi.org/10.1016/S0196-8904(99)00149-1

Bijeljic, B., Mostaghimi, P., \& Blunt, M. J. (2013). Insights into non-Fickian solute transport in carbonates. Water Resources Research, 49, 2714-2728. https://doi.org/10.1002/wrcr.20238

Bijeljic, B., Raeini, A., Mostaghimi, P., \& Blunt, M. J. (2013). Predictions of non-Fickian solute transport in different classes of porous media using direct simulation on pore-scale images. Physical Review E, 87(1), 013011. https://doi.org/10.1103/PhysRevE.87.013011

Buades, A., Coll, B., \& Morel, J. M. (2005). A non-local algorithm for image denoising. Paper presented at the 2005 IEEE Computer Society Conference on Computer Vision and Pattern Recognition (CVPR'05), San Diego, CA, USA. https://doi.org/10.1109/CVPR.2005.38

Celia, M., Bachu, S., Nordbotten, J., \& Bandilla, K. (2015). Status of $\mathrm{CO}_{2}$ storage in deep saline aquifers with emphasis on modeling approaches and practical simulations. Water Resources Research, 51, 6846-6892. https://doi.org/10.1002/2015WR017609

Detwiler, R. L. (2008). Experimental observations of deformation caused by mineral dissolution in variable-aperture fractures. Journal of Geophysical Research, 113, B08202. https://doi.org/10.1029/2008jb005697

Dijk, P. E., Berkowitz, B., \& Yechieli, Y. (2002). Measurement and analysis of dissolution patterns in rock fractures. Water Resources Research, 38(2), 1013. https://doi.org/10.1029/2001wr000246

Ellis, B., Peters, C., Fitts, J., Bromhal, G., McIntyre, D., Warzinski, R., \& Rosenbaum, E. (2011). Deterioration of a fractured carbonate caprock exposed to $\mathrm{CO}_{2}$-acidified brine flow. Greenhouse Gases: Science and Technology, 1(3), 248-260. https://doi.org/ 10.1002/ghg.25

El-Maghraby, R. M., Pentland, C. H., Iglauer, S., \& Blunt, M. J. (2012). A fast method to equilibrate carbon dioxide with brine at high pressure and elevated temperature including solubility measurements. The Journal of Supercritical Fluids, 62, 55-59. https://doi.org/ 10.1016/j.supflu.2011.11.002

Gharbi, O., Bijeljic, B., Boek, E., \& Blunt, M. J. (2013). Changes in pore structure and connectivity induced by $\mathrm{CO}_{2}$ injection in carbonates: A combined pore-scale approach. Energy Procedia, 37, 5367-5378. https://doi.org/10.1016/j.egypro.2013.06.455

Golfier, F., Zarcone, C., Bazin, B., Lenormand, R., Lasseux, D., \& Quintard, M. (2002). On the ability of a Darcy-scale model to capture wormhole formation during the dissolution of a porous medium. Journal of Fluid Mechanics, 457, 213-254. https://doi.org/10.1017/ S0022112002007735

Gouze, P., \& Luquot, L. (2011). X-ray microtomography characterization of porosity, permeability and reactive surface changes during dissolution. Journal of Contaminant Hydrology, 120-121, 45-55. https://doi.org/10.1016/j.jconhyd.2010.07.004

Gouze, P., Noiriel, C., Bruderer, C., Loggia, D., \& Leprovost, R. (2003). X-ray tomography characterization of fracture surfaces during dissolution. Geophysical Research Letters, 30(5), 1267. https://doi.org/10.1029/2002gl016755

He, X., \& Luo, L. (1997). Lattice Boltzmann model for the incompressible Navier-Stokes equation. Journal of Statistical Physics, 88(3-4), 927-944. https://doi.org/10.1023/B:JOSS.0000015179.12689.e4

Iglauer, S. (2011). Dissolution trapping of carbon dioxide in reservoir formation brine-A carbon storage mechanism. In H. Nakajima (Ed.), Mass transfer-Advanced Aspects (pp. 233-262). Rijeka, Croatia: InTech.

Iglauer, S., \& Lebedev, M. (2018). High pressure-elevated temperature X-ray micro-computed tomography for subsurface applications. Advances in Colloid and Interface Science, 256, 393-410. https://doi.org/10.1016/j.cis.2017.12.009

Izgec, O., Zhu, D., \& Hill, A. D. (2010). Numerical and experimental investigation of acid wormholing during acidization of vuggy carbonate rocks. Journal of Petroleum Science and Engineering, 74(1), 51-66. https://doi.org/10.1016/j.petrol.2010.08.006

Kamath, J., Xu, B., Lee, S. H., \& Yortsos, Y. C. (1998). Use of pore network models to interpret laboratory experiments on vugular rocks. Journal of Petroleum Science and Engineering, 20(3), 109-115. https://doi.org/10.1016/S0920-4105(98)00009-6

Lackner, K. S. (2003). A guide to $\mathrm{CO}_{2}$ sequestration. Science, 300(5626), 1677-1678. https://doi.org/10.1126/science.1079033

Lebedev, M., Zhang, Y., Sarmadivaleh, M., Barifcani, A., Al-Khdheeawi, E., \& Iglauer, S. (2017). Carbon geosequestration in limestone: Pore-scale dissolution and geomechanical weakening. International Journal of Greenhouse Gas Control, 66, 106-119. https://doi.org/ 10.1016/j.ijggc.2017.09.016

Li, L., Peters, C. A., \& Celia, M. A. (2006). Upscaling geochemical reaction rates using pore-scale network modeling. Advances in Water Resources, 29(9), 1351-1370. https://doi.org/10.1016/j.advwatres.2005.10.011

Li, L., Salehikhoo, F., Brantley, S. L., \& Heidari, P. (2014). Spatial zonation limits magnesite dissolution in porous media. Geochimica et Cosmochimica Acta, 126, 555-573. https://doi.org/10.1016/j.gca.2013.10.051

Li, L., Steefel, C. I., \& Yang, L. (2008). Scale dependence of mineral dissolution rates within single pores and fractures. Geochimica et Cosmochimica Acta, 72(2), 360-377. https://doi.org/10.1016/j.gca.2007.10.027

Luquot, L., \& Gouze, P. (2009). Experimental determination of porosity and permeability changes induced by injection of $\mathrm{CO}_{2}$ into carbonate rocks. Chemical Geology, 265(1-2), 148-159. https://doi.org/10.1016/j.chemgeo.2009.03.028 
Luquot, L., Rodriguez, O., \& Gouze, P. (2014). Experimental characterization of porosity structure and transport property changes in limestone undergoing different dissolution regimes. Transport in Porous Media, 101(3), 507-532. https://doi.org/10.1007/ s11242-013-0257-4

Maheshwari, P., Ratnakar, R. R., Kalia, N., \& Balakotaiah, V. (2013). 3-D simulation and analysis of reactive dissolution and wormhole formation in carbonate rocks. Chemical Engineering Science, 90, 258-274. https://doi.org/10.1016/j.ces.2012.12.032

Maier, R. S., \& Bernard, R. S. (2010). Lattice-Boltzmann accuracy in pore-scale flow simulation. Journal of Computational Physics, 229(2), 233-255. https://doi.org/10.1016/j.jcp.2009.09.013

Menke, H., Andrew, M. G., Blunt, M. J., \& Bijeljic, B. (2016). Reservoir condition imaging of reactive transport in heterogeneous carbonates using fast synchrotron tomography-Effect of initial pore structure and flow conditions. Chemical Geology, 428, 15-26. https://doi.org/ 10.1016/j.chemgeo.2016.02.030

Menke, H., Bijeljic, B., Andrew, M. G., \& Blunt, M. J. (2015). Dynamic three-dimensional pore-scale imaging of reaction in a carbonate at reservoir conditions. Environmental Science \& Technology, 49(7), 4407-4414. https://doi.org/10.1021/es505789f

Menke, H., Bijeljic, B., \& Blunt, M. J. (2017). Dynamic reservoir-condition microtomography of reactive transport in complex carbonates: Effect of initial pore structure and initial brine pH. Geochimica et Cosmochimica Acta, 204, 267-285. https://doi.org/10.1016/j. gca.2017.01.053

Menke, H., Reynolds, C. A., Andrew, M. G., Pereira Nunes, J. P., Bijeljic, B., \& Blunt, M. J. (2018). 4D multi-scale imaging of reactive flow in carbonates: Assessing the impact of heterogeneity on dissolution regimes using streamlines at multiple length scales. Chemical Geology, 481, 27-37. https://doi.org/10.1016/j.chemgeo.2018.01.016

Miao, X., Zhang, L., Wang, Y., Wang, L., Fu, X., Gan, M., \& Li, X. (2020). Characterisation of wellbore cement microstructure alteration under geologic carbon storage using X-ray computed micro-tomography: A framework for fast CT image registration and carbonate shell morphology quantification. Cement and Concrete Composites, 108, 103,524. https://doi.org/10.1016/j.cemconcomp.2020.103524

Moctezuma-Berthier, A., \& Fleury, M. (2000). Permeability mapping on vuggy core sample using tracer experiments and stream-line simulations. Paper presented at the SPE International Petroleum Conference and Exhibition in Mexico, Villahermosa, Mexico. https:// doi.org/10.2118/58992-MS

Mostaghimi, P., Bijeljic, B., \& Blunt, M. (2012). Simulation of flow and dispersion on pore-space images. SPE Journal, 17(4), 1131-1141. https://doi.org/10.2118/135261-PA

Noiriel, C., Bernard, D., Gouze, P., \& Thibault, X. (2005). Hydraulic properties and microgeometry evolution accompanying limestone dissolution by acidic water. Oil \& Gas Science and Technology, 60(1), 177-192. https://doi.org/10.2516/ogst:2005011

Noiriel, C., \& Daval, D. (2017). Pore-scale geochemical reactivity associated with $\mathrm{CO}_{2}$ storage: New frontiers at the fluid-solid interface. Accounts of Chemical Research, 50(4), 759-768. https://doi.org/10.1021/acs.accounts.7b00019

Noiriel, C., Gouze, P., \& Bernard, D. (2004). Investigation of porosity and permeability effects from microstructure changes during limestone dissolution. Geophysical Research Letters, 31, L24603. https://doi.org/10.1029/2004GL021572

Noiriel, C., Madé, B., \& Gouze, P. (2007). Impact of coating development on the hydraulic and transport properties in argillaceous limestone fracture. Water Resources Research, 43, W09406. https://doi.org/10.1029/2006wr005379

Peng, C., Anabaraonye, B. U., Crawshaw, J. P., Maitland, G. C., \& Trusler, J. M. (2016). Kinetics of carbonate mineral dissolution in $\mathrm{CO}_{2}$-acidified brines at storage reservoir conditions. Faraday Discussions, 192, 545-560. https://doi.org/10.1039/C6FD00048G

Peng, C., Crawshaw, J. P., Maitland, G. C., \& Trusler, J. M. (2015). Kinetics of calcite dissolution in $\mathrm{CO}_{2}$-saturated water at temperatures between (323 and 373) K and pressures up to 13.8 MPa. Chemical Geology, 403, 74-85. https://doi.org/10.1016/j.chemgeo.2015.03.012

Qian, Y., D'Humières, D., \& Lallemand, P. (1992). Lattice BGK models for Navier-Stokes equation. Europhysics Letters, 17(6), $479-484$. https://doi.org/10.1209/0295-5075/17/6/001

Schlüter, S., Sheppard, A., Brown, K., \& Wildenschild, D. (2014). Image processing of multiphase images obtained via X-ray microtomography: A review. Water Resources Research, 50, 3615-3639. https://doi.org/10.1002/2014WR015256

Siddiqui, S., Nasr-El-Din, H. A., \& Khamees, A. A. (2006). Wormhole initiation and propagation of emulsified acid in carbonate cores using computerized tomography. Journal of Petroleum Science and Engineering, 54(3), 93-111. https://doi.org/10.1016/j.petrol.2006.08.005

Smith, M. M., Hao, Y., \& Carroll, S. A. (2017). Development and calibration of a reactive transport model for carbonate reservoir porosity and permeability changes based on $\mathrm{CO}_{2}$ core-flood experiments. International Journal of Greenhouse Gas Control, 57, 73-88. https://doi. org/10.1016/j.ijggc.2016.12.004

Song, W., Wang, D., Yao, J., Li, Y., Sun, H., Yang, Y., \& Zhang, L. (2019). Multiscale image-based fractal characteristic of shale pore structure with implication to accurate prediction of gas permeability. Fuel, 241, 522-532. https://doi.org/10.1016/j.fuel.2018.12.062

Sun, H., Yao, J., Cao, Y. C., Fan, D. Y., \& Zhang, L. (2017). Characterization of gas transport behaviors in shale gas and tight gas reservoirs by digital rock analysis. International Journal of Heat and Mass Transfer, 104, 227-239. https://doi.org/10.1016/j. ijheatmasstransfer.2016.07.083

Szymczak, P., \& Ladd, A. J. C. (2009). Wormhole formation in dissolving fractures. Journal of Geophysical Research, 114, B06203. https:// doi.org/10.1029/2008jb006122

Yang, Y., Li, Y., Yao, J., Zhang, K., Iglauer, S., Luquot, L., \& Wang, Z. (2019). Formation damage evaluation of a sandstone reservoir via pore-scale X-ray computed tomography analysis. Journal of Petroleum Science and Engineering, 183, 106,356. https://doi.org/10.1016/j. petrol.2019.106356

Yang, Y., Tao, L., Yang, H., Iglauer, S., Wang, X., Askari, R., et al. (2020). Stress sensitivity of fractured and vuggy carbonate: An X-Ray computed tomography analysis. Journal of Geophysical Research: Solid Earth, 125(3), e2019JB018759. https://doi.org/10.1029/ 2019jb018759

Yang, Y., Wang, K., Zhang, L., Sun, H., Zhang, K., \& Ma, J. (2019). Pore-scale simulation of shale oil flow based on pore network model Fuel, 251, 683-692. https://doi.org/10.1016/j.fuel.2019.03.083

Yang, Y., Yang, H., Tao, L., Yao, J., Wang, W., Zhang, K., \& Luquot, L. (2019). Microscopic determination of remaining oil distribution in sandstones with different permeability scales using computed tomography scanning. Journal of Energy Resources Technology, 141(9), 092903. https://doi.org/10.1115/1.4043131

Zhang, L., Jing, W., Yang, Y., Yang, H., Guo, Y., Sun, H., et al. (2019). The investigation of permeability calculation using digital core simulation technology. Energies, 12(17), 3273. https://doi.org/10.3390/en12173273

Zhang, L., Nair, N. G., Jennings, J. W., \& Bryant, S. L. (2005). Models and methods for determining transport properties of touching-vug carbonates. Paper Presented at SPE Annual Technical Conference and Exhibition, Dallas, Texas.

Zhang, L., Wang, Y., Miao, X., Gan, M., \& Li, X. (2019). Geochemistry in geologic $\mathrm{CO}_{2}$ utilization and storage: A brief review. Advances in Geo-Energy Research, 3(3), 304-313. https://doi.org/10.26804/ager.2019.03.08 
Zhao, J., Yao, J., Zhang, M., Zhang, L., Yang, Y., Sun, H., et al. (2016). Study of gas flow characteristics in tight porous media with a microscale lattice Boltzmann model. Scientific Reports, 6(1), 1-11. https://doi.org/10.1038/srep32393

Zhu, G., Chen, H., Yao, J., \& Sun, S. (2019). Efficient energy-stable schemes for the hydrodynamics coupled phase-field model. Applied Mathematical Modelling, 70, 82-108. https://doi.org/10.1016/j.apm.2018.12.017

Ziegler, D. P. (1993). Boundary conditions for lattice Boltzmann simulations. Journal of Statistical Physics, 71(5), 1171-1177. https://doi. org/10.1007/bf01049965 